\title{
Evaluating the Effects of Large Scale Health Interventions in Developing Countries:
}

\section{The Zambian Malaria Initiative}

\author{
Nava Ashraf, Harvard University and NBER \\ Günther Fink, Harvard University \\ David N. Weil, Brown University and NBER
}

May, 2010

Since 2003, Zambia has been engaged in a large-scale, centrally coordinated national antiMalaria campaign which has become a model in sub-Saharan Africa. This paper aims at quantifying the individual and macro level benefits of this campaign, which involved mass distribution of insecticide treated mosquito nets, intermittent preventive treatment for pregnant women, indoor residual spraying, rapid diagnostic tests, and artemisinin-based combination therapy. We discuss the timing and regional coverage of the program, and critically review the available health and program rollout data. To estimate the health benefits associated with the program rollout, we use both population based morbidity measures from the Demographic and Health Surveys and health facility based mortality data as reported in the national Health Management Information System. While we find rather robust correlations between the rollout of bed nets and subsequent improvements in our health measures, the link between regional spraying and individual level health appears rather weak in the data.

NAshraf@HBS.edu, GFink@HSPH.Harvard.edu, David_Weil@Brown.edu. We are extremely grateful to David Fiocco and Richard Sedlmayr, who did all the field work required to assemble the data. We are also grateful to Dr. Elizabeth Chizema, Pascalina Chanda, Henry Kansembe, and Dr. Victor Mukonka of the Ministry of Health, to Busiku Hamainza and the National Malaria Control Programme as a whole, and to John Miller of Malaria Control and Evaluation Partnership Africa (MACEPA). Primary funding for this project came from the NBER Project on African Development Successes. Additional funding for data workshops in Zambia was provided by MACEPA, Malaria Consortium, World Bank, and the Zambia Ministry of Health. 


\section{Introduction}

The National Malaria Control Program (NMCP) of Zambia is one of Africa's largest malaria prevention and treatment initiatives. In 2005, the NMCP set the goal of achieving a 75\% reduction in malaria incidence and a $20 \%$ decrease in under-five mortality within five years through a combination of insecticide treated nets, indoor residual spraying, and deployment of rapid diagnostic tests and front-line combination therapy drugs. The total 2008 malaria prevention and control budget, including in-kind contributions, was estimated at $\$ 59.8$ million $^{1}$, including significant aid from the Global Fund to Fight HIV/AIDS, Tuberculosis and Malaria, the United States Agency for International Development (USAID), the World Bank, the World Health Organization (WHO), and the Bill and Melinda Gates Foundation (through the Malaria Control and Evaluation Partnership in Africa-MACEPA).

Figure 1 tells the story of the program's success according to data in Zambia's national health statistics system, the Health Management Information System (HMIS), which we discuss in detail in the next section. The annual number of malaria deaths in the country decreased by at least half over the period 2000-2008, during which population rose by $30 \%$, implying a reduction in the death rate of over $60 \%$. As will be seen below, the number of inpatient visits for malaria declined by a comparable magnitude, implying a reduction in morbidity as well as mortality.

Evidence from the 2001 and 2007 waves of the Demographic and Health Survey confirms the picture painted by the HMIS. The percentage of children under five reported with a fever over the two weeks preceding the interview dropped from $44.6 \%$ in 2001 to $17.9 \%$ in 2007 , a reduction of close to $60 \%$. (As a comparison, the fraction of children suffering from diarrhea fell by only a quarter, from $41.9 \%$ to $31.8 \%$, over the same time period.) The progress made in all-cause child mortality between the two surveys is remarkable: The under-five mortality rate fell from 168 per thousand live births in 2001 to 119 in 2007. As discussed below, the latter figure may not even reflect the full mortality reduction to date. This decline was not solely the result of the malaria initiative, however, since other health campaigns were taking place at the same time.

There are different ways to quantify the magnitude of Zambia's recent success in health improvement. The reduction in under-five mortality represents approximately 25,000 children's lives saved per year. To compare the mortality improvement with more "economic" outcomes, we can do a back of the envelope calculation using the Human Development Index (HDI), which weighs economic and non-economic characteristics into an overall measure of quality of life.

\footnotetext{
${ }^{1}$ Government of Zambia, Ministry of Health. 2008 National Malaria Control Action Plan: Actions for Scale-up for Impact on Malaria in Zambia. Lusaka. All money figures are in US dollars.
} 
Using the formula for the HDI, one can calculate the amount of income growth that would be equivalent to a particular rise in life expectancy at birth. A conservative estimate, using just the data on under-five mortality, is that life expectancy at birth in Zambia rose by 2.25 years over the period 2000-2007. ${ }^{2}$ Plugging this into the HDI formula shows that an equivalent rise in HDI would be achieved if income per capita grew by $25 \%{ }^{3}$

In the research program of which this paper is a part, we study the Zambian malaria initiative with three broad goals. First, we want to systematize and improve the quality of available data on both inputs to malaria control in Zambia and the outcomes of the malaria control program. As will be seen below, much of the available data were not easily interpretable before we began our efforts, so that the review and consolidation of existing data sources became a substantial part of this research endeavor. The second goal of the project is to use the available data from Zambia to examine the causal relationship between inputs into malaria control and health outcomes. Much of the monitoring of the campaign's progress has focused solely on the input and implementation side, with outcome measures such as the number of bed nets distributed or houses sprayed. Jointly analyzing data on inputs and health outcomes allows for some measurement of how well the program is doing in achieving its stated overall health goal, and possibly also for inference about cost-effectiveness. Finally, our third goal (which we do not advance in the current paper) is to use the experience of the current malaria campaign in Zambia to understand the economic effects of malaria and of its control.

The rest of this paper is structured as follows. In Section 2, we discuss our data sources regarding both health outcomes and inputs into malaria control. A good deal of our effort in this project has gone into improving the quality of the data in the Zambia's HMIS, an administrative record system that has the potential to yield richly detailed data, but is also subject to a number of problems. We discuss the HMIS data, how we have tried to help improve it, and the picture of changing malaria impact painted in this improved data. Section 3 describes the background to and scope of the current malaria initiative. Section 4 presents data on how the different components of the initiative have been rolled out, focusing in variation among different regions. In Section 5, we attempt to assess the link between data on the rollout - that is, inputs to reduced malaria - and data on improvements in malaria mortality and morbidity, using both the HMIS and the Zambian Demographic and Health Surveys (DHS). Section 6 concludes by discussing

\footnotetext{
${ }^{2}$ This is based on multiplying a one in twenty reduction in under five mortality by 2000 life expectancy at birth, which was approximately 45 years.

${ }^{3}$ The HDI is the sum of three terms, two of which are $\frac{e_{0}-25}{60}$ and $\frac{\ln (y)}{\ln (40,000)-\ln (100)}$, where $e_{0}$ is life expectancy at birth and $y$ is real GDP per capita. The change in income that has the same impact on HDI as a particular change in life expectancy is given by the equation $\Delta \ln (y)=\frac{\ln (40,000)-\ln (100)}{60} \times \Delta \mathrm{e}_{0}$.
} 
avenues for future research and also the challenge of sustaining the progress made in Zambia over time.

\section{Data on Malaria and Other Health Outcomes}

In this paper we rely on two data sources: first, the 2001 and 2007 waves of the Demographic and Health Survey (DHS), and second, the Zambian Health Management Information System (HMIS). ${ }^{4}$

\subsection{DHS data}

Our first source of data are the 2001 and 2007 waves of the Zambian Demographic and Health Survey (ZDHS). For our analysis, we use the children recode files, which contain detailed information on all children under age 5 at the date of the interview as well as a complete list of household and respondent characteristics. We have 13,219 child observations, 6,877 from 2001, and 6,342 from 2007.

To link the DHS households to the NMCC's rollout data, we used ArcGIS to map DHS cluster locations into the respective districts. All 72 districts were covered in the 2001 survey; 70 out of 72 were covered in 2007.

\subsection{HMIS data}

The national Health Management Information System (HMIS) captures an impressive amount of routine health data. The database was first introduced in 1995 to collect disease data, service delivery information, and clinic operations reports. It provides data on health outcomes in the vast majority of Zambia's health facilities. These range in size from hospitals (located in 60 of the 72 districts in Zambia) to small health posts staffed by a single nurse or community health worker. ${ }^{5}$

The database has recently been subject to major technical revisions, resulting in a system with a monthly reporting structure and new management software that captures additional indicators, including separate measures for confirmed and unconfirmed malaria cases. Officially

\footnotetext{
${ }^{4}$ A third potential source of data is the Malaria Indicators Survey (MIS) conducted in 2006 and 2008. The MIS collects data on household uptake of anti malarial measures (such as use of bed nets and IRS) and health outcomes such as child sickness. However, this data was not available for our use at the time of this writing.

${ }^{5}$ Lusaka's referral hospitals are not included in the HMIS in order to prevent redundancy; theoretically, every person seen in such a hospital should have already been recorded at another hospital or health center.
} 
the new HMIS became the primary reporting system beginning January 2009. Most districts transitioned into the new system by reporting in both formats for some part of 2008 . Using historical data however, the analysis presented in this paper is based on files from the "old" HMIS. The following description relates to this original system.

Traditionally, health data were passed from each of the reporting health facilities to the respective district office (72), and then passed on from the district to the regional offices (9 in Zambia). The facilities kept both hard copy patient logs and tally sheets that track clinic functions. At the end of each quarter, facilities reported their summary data to district offices. District health information officers were charged with collecting the reports from each health facility and compiling district reports. They were responsible for ensuring all health facilities had reported, as well as cleaning each facility's data.

Provincial data management specialists collected data from the districts and compiled a provincial data set disaggregated at the facility level. Before forwarding the data on to the national level, the provincial officers once again cleaned the data and verified it for completeness. The provincial data sets were compiled into a unified national data set at the Ministry of Health's headquarters. This data set remained disaggregated at the facility level.

Given the multi-level reporting system, the potential for error was relatively large in the original system, and the quality of health facility data was dependent on staff and their commitment to record keeping. Some health facilities had been meticulous about their record keeping, plotting their health outcomes manually and discussing them in meetings. Others had not been able to keep records in conjunction with patient visits, or had delegated reporting requirements to semi-literate staff. In some cases, tally sheets were only updated on a monthly basis and figures estimated when regular reporting was limited.

The transfer from health facility paper records to electronic district summaries was also error-prone. The original HMIS database had no built-in consistency checks for disease data, and data were entered only once, without systematic data verification ${ }^{6}$

\footnotetext{
${ }^{6}$ The data verification and cleaning exercises by officers at the district and provincial levels did not follow systematic guidelines, and the quality of these activities depended heavily on their training. In addition, as the task division followed geographical boundaries, workloads were split very unevenly: some district officers were responsible for less than ten facilities, others for more than forty.
} 
Quarterly updates from districts to provinces were then processed centrally, with only the most recent quarter received from the provinces appended to previous data. However, even after initial submission deadlines, data staff at sub-national levels continued to work on assembling missing data and auditing reports. As a result, changes subsequently made at the district or province level were lost in the national data set. When data were cleaned at the district and provincial levels, revised data sets were not returned to the original sources of the data. Consequently, major inconsistencies existed between the data sets at different levels of the health system.

\section{Improvement of the HMIS}

Ultimately, the HMIS is the only source of consistent national health data. Selected surveys (especially the Demographic and Health Surveys and the Malaria Indicator Surveys) provide more accurate snapshots of malaria levels in select districts at given times, but only the HMIS allows for detailed, localized analysis of malaria levels over time. With this in mind, a major goal of this project was to improve and validate the HMIS data as much as possible.

To facilitate this data improvement goal, the project team conceptualized a series of malaria data verification workshops; in collaboration with the National Malaria Control Centre one HMIS workshop was organized in each of Zambia's nine provinces. In preparation for these workshops, we systematically scanned HMIS data for outliers and suspicious data points (duplicate figures, significant variance between quarters or years, reporting inconsistencies). District health officials were asked to find missing reports and justify all irregular data ahead of the workshops. This data audit served as one of the final updates of health data from 2000 to 2008, ahead of its transition into the new HMIS system. ${ }^{7}$

The workshops also provided an opportunity to reconcile incomplete or mismatching data on malaria prevention and treatment campaigns at the district level. Districts were asked to visit each health facility in an attempt to capture all malaria interventions within the facility's catchment area by government and non-government partners. District pharmacists provided distribution data on treatment courses and diagnostic tests at local health facilities, while environmental health technicians provided data on IRS activities. During the workshops, these data were pooled with health outcomes, presented, and discussed by the district staff. Subsequently, it could be used by the project team to plausibility-check the national data sets.

\footnotetext{
${ }^{7}$ These resulting changes sometimes had major implications for national level trends. For instance, in the uncorrected HMIS, under-five malaria deaths rose from 3,342 in 2006 to 3,783 in 2007. These figures were reported in the 2008 World Malaria Report, among other places. The workshops showed that the reported increase was due to three districts with erroneous figures. In the fully corrected HMIS, under-five malaria deaths fell from 3,235 in 2006 to 2,680 in 2007.
} 
In total, the nine provincial workshops were conducted at a total cost of approximately $\$ 200,000$. Funding was provided by the Malaria Consortium and MACEPA, as well as the National Malaria Control Centre with support from a World Bank Grant. The workshops brought together a diverse array of district health personnel, including district information officers, malaria focal point persons, and district directors of health. Provincial and national health officers also attended each workshop. In total, over 250 attendees were trained in various aspects of data collection, cleaning, and analysis.

The workshops resulted in a more complete, correct, and consistent HMIS database for the years 2000 through 2008, as outlined in Table 1. In terms of completeness, the original national-level HMIS files that we received ahead of the workshops had 3,318 records marked as missing (out of a total of approximately 45,000 facility quarterly reports that should have been present). Over the course of the malaria data verification workshops, 1,901 missing quarterly reports could be retrieved. Also, data were added on 28 facilities that had no HMIS records altogether, bringing the total number of facilities in the system to 1,501. Reviewing apparent data entry errors ahead of the workshops allowed district staff to conduct major revisions. Finally, the most recent versions of the district's HMIS databases were disseminated to the national level, thereby ensuring consistent insights for both local and central decision-making.

While the workshops resulted in a higher quality HMIS data set, they also built local capacity through several days of training to on how to compile and analyze integrated health databases. Participants were encouraged to challenge each other's presentations, and lively debates were common. In many cases, these workshops provided the first opportunity for district

medical officers to use data to consider the effects of interventions they had implemented and create strategic plans for future interventions. Data analysis capabilities empower local staff and generate decentralized interest in accurate and complete data; thiswas considered a promising approach by the Ministry of Health and its partners, andfollow-up workshops have since been initiated in several provinces.

\subsubsection{Remaining Issues in the HMIS Data}

\section{Diagnosis and Access to Health Facilities}

The number of malaria cases that are reported in HMIS is potentially biased by several factors that cannot be readily uncovered in the data. The first issue is inconsistencies in diagnostic practices over time. The HMIS is supposed to report all outpatient and inpatient visits, broken down by diagnosis. The problem is that the way in which malaria is diagnosed has changed over the period we examine. Because of both lack of diagnostic technology and differential treatment guidelines, a majority of fevers in Zambia were traditionally classified (and treated) as malaria. As discussed in further detail below, the rollout of the national anti-malaria 
initiative has included the massive deployment of rapid diagnostic tests (RDTs) to health centers, in order to economize on malaria treatment and properly treat non-malaria fevers. The deployment of RDTs would have led to a reduction in diagnosed cases of malaria even if there was no true change in disease prevalence, as well as an increased diagnosis of other conditions, such as respiratory tract infections. Since the method of diagnosis is not tracked in the original HMIS, quantifying the magnitude of this "diagnostic effect" is not straightforward.

Another bias from diagnosis concerns HIV/AIDS. With HIV/AIDS highly stigmatized, anecdotal reports from the clinics suggest that a considerable fraction of HIV deaths were officially classified as malaria mortality. Given the large inflow of foreign funding for HIV treatment over the last five years, HIV mortality has fallen substantially, which may have contributed to the officially recorded declines in malaria mortality.

Another issue is that the accessibility of the health system changed over time. This is most dramatically shown in outpatient data for adults in rural facilities. A large increase in this variable is recorded in 2006, which can likely be attributed to the abolition of user fees in rural health clinics in the same year. Prior to 2006, all public-sector patients were expected to pay nominal fees for consultations, diagnostic tests and some drugs supplied in government clinics. In 2006, all consultation and diagnostic fees were removed for patients living in designated rural areas. It is likely that prior to the elimination of user fees, many would-be outpatients had resorted to self-treatment.

To minimize the bias from such contextual factors, we focus on severe cases specifically, inpatient malaria cases, reported malaria deaths, and reported total deaths. In the HMIS, diagnostic codes for inpatients are entered only at the time of discharge or death. We think that even prior to the abolition of user fees or the advent of RDTs, severe cases would have received inpatient treatment and would have been correctly diagnosed most of the time (prior to the advent of RDTs, malaria diagnoses could be confirmed using microscopy at many clinics and hospitals treating severe malaria).

\section{Extent of HMIS Coverage}

A potential worry about the HMIS is that it only measures cases that enter the government's health system. To the extent that this is a small fraction of total cases, one would worry both that it is non-representative and, more seriously, that the fraction of cases captured by the HMIS varies over time. In the latter case, the use of the HMIS to measure trends in disease prevalence would be seriously compromised.

One way to measure the fraction of cases that the HMIS captures is to focus on deaths, because in this case there is the possibility to use other data sources as a benchmark. Figure 2 
shows the under-five death rate (annual deaths of children under five in the HMIS per 1,000 children; population data are estimates from Ministry of Health). The data for the full sample show a relatively steady decline from 8.46 in 2000 to 5.05 in 2007, followed by a precipitous decline to 3.26 in 2008. This last figure may represent incomplete reporting for 2008. In the high quality sample (where we use only consistently reporting facilities as discussed below), the trend from 2000-2007 is roughly similar, but the decline in 2008 is smaller, suggesting that increasing under-reporting might indeed be an issue for the aggregate 2008 data.

We can compare the count of deaths in the HMIS to both the DHS and to other mortality estimates. Most estimates of child mortality are expressed in terms of deaths before age five per 1,000 live births. To convert the HMIS data to this metric, we simply multiply the number of under 5 deaths per 1000 by five (this is a slight over-estimate because the number of children declines with age due to population growth and mortality.) Thus in the HMIS data, the child mortality rate was approximately 42.3 per 1,000 children under 5 in 2000, and 25.3 in 2007; deaths declined by $40.2 \%$. In the DHS, deaths per thousand live births were calculated at 168 in 2001-2 and 119 in 2007, implying a decline of $29 \% .{ }^{8}$ Other published estimates of child mortality show numbers similar to the DHS for 2000, but do not show the same decline as observed in the HMIS and DHS. For example, WHO World Health Statistics 2009 lists the under five mortality rate for Zambia as 178 in 2000 and 170 in 2007. It is not clear what the source for these numbers is, although other WHO publications rely on the DHS estimate for the year 2000. We suspect that the lack of decline in these published figures reflects non-availability of data, rather than information from an alternative source.

Using either the DHS or WHO number for 2000 as a benchmark implies that the HMIS in that year is capturing between a fifth and a quarter of deaths under age five. In terms of the change between 2000 and 2007, the HMIS shows a larger decline than the DHS, although in both cases the magnitude is impressive. Further, it is important to note that the DHS measures underfive mortality by looking at the experience of all children born in the last five years. Thus the number from the 2007 DHS includes children born in 2003, whose early life (when mortality is highest) was not impacted by the malaria initiative. Thus it is expected that the decline in the HMIS would be larger. If instead of using the HMIS death rate in 2007, we use the average death rate from 2003-2007, then the decline in under-five mortality in the HMIS is $29 \%$, exactly matching the DHS.

The low representation of total deaths in the HMIS suggests several possible biases. Presumably the fraction of disease episodes and deaths that reach a clinic or hospital is higher in

\footnotetext{
${ }^{8}$ Zambia DHS Final Report, March 2009, http://www.measuredhs.com/pubs/pdf/FR211/FR211[revised-05-122009].pdf
} 
urban regions than in remote, rural areas. ${ }^{9}$ Since malaria is higher in rural regions, this suggests that malaria deaths are understated in the HMIS data. Regarding the change in malaria prevalence as a result of the anti-malaria initiative, sorting out the bias is more difficult. On the one hand, the intensity of the program was probably highest in the same areas (places with health facilities nearby) that are overrepresented in the HMIS. This might suggest that the HMIS data would overstate the impact of the program. On the other hand, areas that were near clinics, especially cities, were likely relatively better served and had lower malaria impact prior to the initiative. Thus the HMIS data may be underweighting places where the largest scope for impacting malaria incidence.

To further investigate the bias from undercounting in the HMIS, Figure 3 compares under- five mortality by province in the DHS and HMIS. The data from the DHS are the underfive mortality rates for 2007. From the HMIS, we take under-five deaths in 2007, divided by an estimate of under-five population, then multiplied by five to make a figure consistent with the DHS measure. The extent to which the ratio of HMIS to DHS deaths differs among provinces is quite surprising. At the high end, in the Copperbelt province, HMIS deaths are $32 \%$ of those implied by the DHS. At the low end, in Lusaka, deaths in the HMIS are only $6 \%$ of those implied by the DHS. The explanation for the low fraction of deaths recorded in the HMIS in Lusaka is that the city's two major hospitals are not included in the HMIS since they are considered referral hospitals and not primary health facilities. However, most critical patients in the Lusaka area would end up in one of the referral hospitals. Theoretically, all patients are supposed to be seen at another health center prior to admission to these hospitals, and the hospital is supposed to report back to the referring center with the patient's outcome for entry into the HMIS. The available data suggests that the final treatment outcomes at the referral centers do not make it back into the referring center's HMIS records.

To check whether undercounting in the HMIS might bias conclusions regarding changes in malaria over time, Figure 4 compares the province-level change in under-five mortality in the DHS between 2001 and 2007 with the change in deaths in the HMIS per 1,000 children under five. The fit is relatively good (correlation 0.76 ). This gives us confidence that changes in the HMIS reflect actual changes in malaria mortality and morbidity.

\section{Non-reporting facilities}

\footnotetext{
${ }^{9}$ In $2005,36.5 \%$ of the population lived in urban areas (though presumably a smaller fraction of the under-five population).
} 
A final concern with the corrected HMIS is the potential confusion between health facilities that have no cases to report and cases where data are actually missing. Upon conclusion of the malaria data verification workshops, the HMIS had data on 1,501 health facilities reporting at some point between 2000 and 2008. Each quarterly record has number of in- and outpatients under and over age five, as well as the number of deaths for up to 59 diseases - the total number of diseases recorded in the HMIS is 71 . About $20 \%$ of reporting health facilities deal only with outpatients. Many of the remaining facilities have incomplete reporting. To make sure our results are not affected by differences in reporting, we construct a high quality sample consisting of 253 large hospitals with at least one patient reported in each quarter between 2000 and 2008 - a sample of 9108 quarter-year observation at the hospital level. To the extent that missing entries represent true zeros (no report because there was no malaria), this sample will lead to an underestimate of the true effects, as hospitals with few malaria patients might discontinue reporting malaria due to the observed declines.

Table 2 shows data on inpatient visits and deaths broken into age groups (under-5 and $5+$ ), separately for malaria and for all non-malaria conditions. We show the data both for all facilities, and for the set of "always reporting" facilities. The table shows that, as discussed below, the decline in malaria prevalence has come at the same time as a dramatic improvement in health more generally, due primarily to massive scale up of HIV treatment and child health programs.

Another notable feature is that among the group of all facilities, there is an apparently discontinuous drop in both in-patient visits and mortality, both for malaria and other conditions, in the year 2008. Among the always-reporting facilities, there is a smaller drop in malaria cases and deaths as well as in non-malaria conditions. It is possible that this is due to reporting problems in non-always-reporting facilities. There is a particular drop off in the number of facilities providing non-zero reports in the last two quarters of 2008. We believe this is due to both the switch over to the new HMIS and to delays in facility reports reaching Lusaka. For these reasons, we assign little credence to the all-facilities drop in mortality in 2008.

In Figure 5 we look at an alternative to the always reporting facilities. We construct a chain index by looking for every pair of adjacent years at the full set of facilities that report in both years. The overall story told in this data is not very different from the always reporting facilities. From 2000 to 2008, under-five malaria deaths fall by $66 \%$ and deaths of people aged five and above fall by $59 \%$. The figure also shows a spike in over-five outpatients diagnosed with malaria in 2006, a phenomenon that may be associated with the abolition of user fees, as discussed above.

As a final, very conservative way to look at the decline in malaria, we examine the ratio of malaria deaths to non-malaria deaths in Figure 6. We do this for different age groups and for 
both all facilities and the always-reporting facilities. If there were no actual improvement in non-malaria health outcomes, and the decline in non-malaria mortality in the HMIS reflected only reporting problems, then this measure would nonetheless correctly measure the decline in malaria mortality. As the figure shows, the ratio of malaria to non-malaria mortality fell by between $1 / 3$ and $1 / 2$ over this period.

\subsubsection{Seasonality in the HMIS}

As a check on the quality of the data in the HMIS, and also to exploit some of its richness, we look at seasonal variation in the malaria incidence. Table 3 shows the results of a basic regression with quarterly under 5 mortality as dependent variable with quarter and year fixed effects. ${ }^{10}$ Figure 7 plots the coefficients on the quarter dummies for both total mortality and malaria mortality. The seasonal fluctuations are strong, and are consistent with Zambia's climate, as discussed below. With an average under- 5 death rate of 1.75 per 1000 , a negative coefficient of -0.7 in quarter three implies that the death burden in the best quarter is only about $60 \%$ of the death burden in the worst quarter (quarter 1). These seasonal fluctuations are even more pronounced for malaria. Overall, about half of the seasonal fluctuation in under-five mortality is driven by malaria.

In columns 2 and 4 of Table 3, we divide the sample in the middle and estimate quarter dummies separately for the two halves. Figure 8 shows the interacted quarter dummies for malaria mortality while Figure 9 shows the quarter dummies for all-cause mortality. What we find is that the seasonality of both has gone down. Indeed, the coefficients show that the decline in seasonality in malaria deaths (a change in .227 deaths per thousand in the worst quarter relative to the best) is more than $2 / 3$ of the decline in the seasonality of total deaths ( .317 deaths per thousand in the worst quarter relative to the best). Malaria accounted for approximately $29 \%$ of under-five deaths over the entire sample period, so the large share of malaria in the decline in seasonality is not simply a reflection of the overall decline in the death rate.

\section{Origins and Scope of the Zambia Malaria Control Program}

Zambia is a land-locked country in Southern Africa with three distinct seasons: a hot, dry season from late August to October; a warm, rainy season from approximately November to April; and a cool, dry season stretching from May to early August. In the cool season temperatures can be as low as 10 degrees Celsius ${ }^{11}$, with both the lack of rain and the cool

\footnotetext{
${ }^{10}$ Note that this is deaths in a quarter divided by the under five population, so its mean is one-quarter of the underfive death rate reported in Table 2/Figure 1.

${ }^{11}$ Data provided by the Zambian Meteorological Department.
} 
temperatures hindering mosquito reproduction; as such, reported cases of malaria are the lowest during the third quarter of the year. Traditionally malaria transmission is highest in the first and fourth quarters, peaking in March towards the end of the warm, rainy season. The swampy Luapula Province in Zambia's North remains the region's hotspot, though malaria is traditionally endemic throughout the country.

As discussed in Packard (2007), the malaria situation in Zambia prior to the current campaign was rather critical from a recent history perspective. Annual malaria incidence rose from 121 per 1,000 in 1976 to 376 per 1,000 in 2000. Among the factors that contributed to this deterioration were Zambia's role as a front-line state in the struggle against apartheid, international constraints on the use of DDT, and the country's broader economic decline (GDP per capita at PPP rose from $\$ 954$ at independence in 1964 to $\$ 1,235$ in 1970 and peaked at $\$ 1,474$ in 1976. It then declined, reaching a nadir of $\$ 829$ in 1995 before rising to $\$ 946$ in 2003. ${ }^{12}$ ) Zambia's malaria control program had relied extensively on Indoor Residual Spraying, but by 1990 spraying had ceased altogether. In addition, resistance to chloroquine started to emerge rapidly across the country.

The beginning of the current anti-malaria initiative was a result of a confluence of factors both in Zambia and elsewhere in the world. In particular, the development of new technologies and a new alignment of priorities within the development community led to a desire to undertake a demonstration case showing the possibility of rapidly scaled up malaria control. Resources would be concentrated on a single country with the goal of producing a tangible success, which would then serve as a model for neighboring countries. Zambia was chosen as the test case because it was perceived as having the institutional capacity and political will to successfully undertake such a program and also because its climate made it all the more likely that success could be accomplished.

\subsection{Elements of program}

Zambia's integrated malaria control program is one of the world's largest national treatment and prevention plans. The program is led by the National Malaria Control Centre (NMCC), a sub-division of the Department of Public Health and Research within Zambia's Ministry of Health. The national secretariat is responsible for overall program administration throughout the country and disburses funds to districts on a programmatic basis. The NMCC works in partnership with Medical Stores (a quasi-private national distribution program for all

\footnotetext{
${ }^{12}$ Penn World Tables, version 6.2. Variable RGPCH in year 2000 constant international dollars. GDP per capita rose a further 16 percent in total from 2003 to 2007 (World Development Indicators database), on the back of soaring copper prices. The price of copper fell by $60 \%$ in the year to February 2009, suggesting that Zambia will be particularly hard hit in the current world slowdown.
} 
drugs and medical supplies in the public sector) to ensure that each district and referral hospital receives adequate supplies of drugs and diagnostic tools. Seventy-two District Medical Offices (previously "District Health Offices") directly implement most national malaria prevention and treatment programs. The districts are grouped into nine provinces, each with a Provincial Health Office responsible for supervising district health programs.

The program is funded by a collaboration between the Government of Zambia and national as well as international partners. From its own revenues and various support lines, the Government of Zambia budgeted \$25.4 million for the Department of Public Health's Malaria Control \& Management activities in $2008 .{ }^{13}$ This amounted to $61 \%$ of the department's budget. The total 2008 malaria prevention and control budget, including in-kind contributions from nongovernmental institutions, was estimated at \$59.8 million, ${ }^{14}$ though actual contributions may not have always matched pledges or projections.

The largest component of the 2008 budget was the provision of insecticide-treated mosquito nets (ITNs). The $\$ 32.0$ million allocated to this activity accounted for $54 \%$ of the NMCP's overall 2008 budget, although budget allocations did not always match actual expenditure, sometimes due to donors failing to deliver on their commitments. For example, in 2008, the government budgeted for 3.5 million nets but ended up distributing only about one million; only $1 / 6$ of the Ministry of Health funds budgeted for nets in Lusaka, Copperbelt, and Central provinces were actually expended.

Of all the malaria prevention modalities of the program, bed nets suffer from the greatest problem in terms of a mismatch between distribution and effectiveness. The standard guideline is that every person living in a household not sprayed with indoor residual spraying should sleep under a bed net. However, utilization remains well below the $85 \%$ target. Some report sleeping under a bed net to be uncomfortably hot or claustrophobic, while others report irritation to the chemical treatments. There are also frequent reports of people not using nets at all, sometimes keeping them packaged as a sign of wealth or using them for other purposes (such as wedding veils and fishing nets), but there has been no systematic study to measure full utilization levels.

The other primary preventive intervention, indoor residual spraying (IRS), was carried out in 36 of Zambia's 72 districts in $2008^{15}$, targeting primarily urban and peri-urban areas with relatively high population densities. Its projected cost was $\$ 8.6$ million in 2008 .

\footnotetext{
${ }^{13}$ Government of Zambia. Estimates of Revenue and Expenditure: Activity-Based Budget 2008. Lusaka.

${ }^{14}$ Government of Zambia, Ministry of Health. 2008 National Malaria Control Action Plan: Actions for Scale-up for Impact on Malaria in Zambia. Lusaka.

${ }^{15}$ As described in further detail below, IRS spraying was originally only targeted to a handful of urban areas across the country and only slowly scaled up over time.
} 
Treatment is another major component of the national malaria control program. The NMCC's strategic plan targets achieving "Prompt and Effective Case Management" (PECM), with a goal of ensuring that at least $80 \%$ of malaria patients receive effective treatment within 24 hours of the onset of symptoms. After noting decreasing efficacy of Sulphadoxine/ pyrimenthamine (SP) and chloroquine, Zambia became one of the first countries to introduce artemisinin-based combination therapy (specifically artemether plus lumefantrine, with the brand name Coartem $\left.{ }^{\circledR}\right)$. ACTs, free in the public sector, became the first-line treatment for all malaria cases during the 2002-2003 malaria transmission season, but it wasn't until the 2005-2006 season that the drug reached all districts in the country. Until 2007 the country faced continuing challenges to retain national stocks. The national supply stabilized in 2007; since that time there have not been complete national stock-out periods, though logistical challenges in distribution to the provinces, districts and health facilities still remain (Sipilanyambe et al. 2008).

The total allocation for PECM in 2008 was $\$ 11.1$ million, approximately $19 \%$ of the total program budget. Of this money, $\$ 2.6$ million was designated for malaria diagnostics, primarily for the purchase of 2 million rapid diagnostic tests (RDTs). The procurement of 3.8 million courses of Coartem ${ }^{\circledR}$ was the largest component of the case management budget, costing $\$ 5.3$ million (note that Coartem ${ }^{\circledR}$ is heavily subsidized by its manufacturer, Novartis).

In the public sector, national treatment guidelines dictate Coartem ${ }^{\circledR}$ as the first line of treatment, with quinine (available in tablets and intravenously) reserved for those who fail to respond to Coartem ${ }^{\circledR}$. Chloroquine and Fansidar ${ }^{\circledR}$ (a combination of Pyrimethamine and Sulphadoxine) are no longer to be used for malaria treatment in the public sector, though Fansidar ${ }^{\circledR}$ remains the indicated preventive treatment given to pregnant mothers. In practice, however, Fansidar ${ }^{\circledR}$ is often used as a first or second line treatment for patients, especially for those who have negative malaria test results.

When ACTs were introduced in 2003, the high initial cost of the drug prompted an effort to improve diagnostics to control the drug prescriptions. In addition to promoting the increased availability of microscopes and trained laboratory technicians, rapid diagnostic tests (RDTs) were first purchased in 2004 for facilities where microscopes were unavailable. RDTs are simple testing devices allowing malaria diagnosis by a health worker with limited training in just fifteen minutes. Global production of RDT kits rose from roughly 3 million in the year 2000 to 28 million units in 2005 (Frost and Reich, 2008).

There is an important interaction between availability of RDTs and use of ACTs. When RDTs are not available, there is a strong tendency for health workers to treat all fevers as malaria (as it was previously suggested by the WHO), and dispense ACTs accordingly. When RDTs are present, a significant fraction of fevers are determined not to be malaria. Until 2007, the national Integrated Management of Childhood Illnesses (IMCI) guidelines dictated that all children under 
5 with fevers were to be presumptively treated for malaria. National malaria policy guidelines revised in 2008 state that it is against national policy to dispense Coartem ${ }^{\circledR}$ to any patient weighing more than $5 \mathrm{~kg}$ (about 3 months old) without a confirmed malaria diagnosis through RDT or microscope. However, reaching compliance among clinicians with this remains one of the biggest challenges in the national program. A 2007 study found that of $58.4 \%$ of patients with a negative blood smear and $35.5 \%$ of those with a negative RDT result were prescribed an antimalarial drug (Hamer et al. 2007). 2008 performance assessments at health facilities reveal that some centers are still not using RDTs at all. Unlike Coartem ${ }^{\circledR}$, which is on a "push" system and comes to the clinic whether they request it or not, RDTs are on a "pull" system and need to be requested. Data compiled at our malaria workshops shows that the availability of RDTs is associated with greatly lower reported cases of malaria and lower use of ACTs.

The wholesale price of RDT is about \$.70, and for ACTs is roughly in the same range (Frost and Reich, 2008). Even though these prices would seem to say that there is no point in using RDTs before dispensing ACTs in order to save on costs, the public health benefits of not overusing ACTs are enormous, since restricting use will prevent the development of resistance. In addition, ruling out malaria allows for better management of negative cases.

Smaller components of the 2008 budget included: Information, Education, Communication/ Behavior Change Communication (IEC/BCC), and Advocacy (\$2.2 million), Monitoring and Evaluation (M\&E) (\$2.2 million), Operations Research (\$986,178), Emergency and Epidemic Malaria Preparedness Plan (\$982,000), and Entomological Activities $(\$ 800,400)$. $\$ 877,507$ was allocated for program management at the national secretariat.

A 2008 health facility census recorded 1,554 health facilities, including public, private and church-run health centers. Two thirds of these facilities are located in Zambia's rural areas. There are 98 referral hospitals in the country. ${ }^{16}$ All districts have an active cadre of lay community health workers (CHWs) who supplement permanent health centers. However, the level of care CHWs can provide varies widely by district. A current Home Management of Malaria initiative (HMM) seeks to train CHWs to administer rapid diagnostic tests and provide artemisinin-based combination treatment to patients at their homes; the program is currently being scaled up, but continues to face logistical difficulties in providing drugs and supplies to all trained volunteers.

\subsection{Non-malaria changes in the Zambian Health}

As mentioned above, the anti-malaria initiative was not the only change in the Zambian health environment over the period we examine. During the period 2003-06 there were a series

\footnotetext{
${ }^{16}$ Government of Zambia, Ministry of Health. Health Facilities in Zambia: A Listing of Health Facilities According to Level and Location for 2008. Lusaka: February 2008.
} 
of other health programs occurring, mostly in HIV, tuberculosis, and child health. In addition, the reduction in malaria may have led to decreases in other diseases either through reduced comorbidity or through the freeing up of resources within the health care system.

In 2004, funds from the US President's Emergency Plan for AIDS Relief (PEPFAR) began arriving in Zambia. According the US Embassy, PEPFAR funds in Zambia were \$149 million in 2006, which was spent on prevention, treatment, and care. One targeted area for spending was prevention of mother-to-child transmission, which has the potential to sharply reduce child mortality.

While the efforts to combat child mortality by reducing tuberculosis and the transmission of HIV to children have undoubtedly contributed to the declines in child mortality observed, the interactions between these two diseases and malaria are hard to pin down. One of the main effects of childhood exposure to malaria is anemia, which makes children more vulnerable to other diseases such as tuberculosis and diarrhea. The same could clearly be said the other way around: progress made in terms of diarrheal diseases or tuberculosis means healthier children with better immune systems.

\section{Rollout of the program}

\subsection{National Data}

Table 4 shows the rollout of the three key pieces of the malaria prevention program: ITNs, IRS, and RDTs. ${ }^{17}$ The table shows the degree to which the program accelerated in 2006 and 2007. Half a million nets were distributed in 2003, but only 176,082 in 2004 (the low number has been attributed to foreign donors failing to provide them that year). The number returned to half a million in 2005, then 1.2 million in 2006 and 2.4 million in 2007. ${ }^{18}$ As discussed above, the decline in bed net distribution in 2008 was not planned as of the beginning of that year. There were to have been 3.5 million nets distributed. Starting in early 2007, all bed nets distributed were Long Lasting Insecticide Treated Nets (LLITNs), which according to the WHO and NMCC can last for multiple washes and several years (beyond their expected lifetime of three years) without insecticide retreatment.

\footnotetext{
${ }^{17}$ National Malaria Control and Scaling Up for Impact: The Zambia Experience through 2006 Richard W. Steketee, Naawa Sipilanyambe, John Chimumbwa, James J. Banda, Abdirahman Mohamed, John Miller, Suprotik Basu, Simon K. Miti, and Carlos C. Campbell

${ }^{18}$ NMCC and WHO say any Long Lasting Insecticide Treated Net are effective if distributed in the last 3 years. Earlier nets given that were not treated lasted for shorter periods of time, but some retreatment kits were distributed for those nets.
} 
In the initial design of the malaria initiative, IRS was to be restricted to only areas of very high population density. The scope of IRS was expanded in discrete jumps through 2008 (see Figure 10). The number of households increased dramatically (almost ten-fold) between 2004 and 2008 . By the latter year, roughly $43 \%$ of the population was covered by spraying. IRS is generally conducted at the end of the calendar year, before the onset of the rainy season when malaria is high. IRS must be re-applied each year.

The shift in strategy toward increased reliance on IRS was driven by two factors: first, it is seen as more cost effective. Second, reports of low utilization of bed nets were perceived as a major problem. IRS, once applied, does not require active uptake by the household.

The last column of Table 4 shows the rapid growth of RDT use, which only happened at the very end of our sample period.

According to the 2007 DHS, 91\% of women in urban areas and $84 \%$ rural took some form of anti-malarial treatment during their last pregnancy and 68\% (61\% rural) received IPT during an ante-natal visit. On average $38 \%$ of women used IPT in the 2001 DHS.

\subsection{Regional variation in the rollout}

The fundamental strategy of the anti-malaria initiative was to push distribution and use of bed nets in high-malaria, rural areas. Initially, IRS was targeted only at urban areas; later the scope of IRS was expanded to include half the districts in the country.

\subsubsection{ITNs}

The NMCC goal is to ensure that $100 \%$ of households in non IRS-targeted areas have at least one mosquito net for every two people, with utilization rates of at least $85 \%$. Insecticidetreated mosquito nets are distributed by the NMCC directly and through a number of partners to specific populations. Programs target mothers and infants, vulnerable populations (orphans, economically deprived populations, HIV+/AIDS patients), and the general public through commercial and subsidized sales, targeted distributions and free mass community distributions. Table 5 compares the DHS and NMCC database at the provincial level. The first two columns are based on NMCC data on the number of nets distributed (total and per capita) by province. The 2001 DHS finished collecting data in May 2002, while the 2007 DHS began collecting data in April of that year. The number of nets in the table is the total from quarter 3 of 2002 through quarter 1 of 2007 . The next three columns use data from the 2001 and 2007 waves of the DHS on the fraction of children under five living in a house with at least one bed net. It is not clear whether one would expect a bigger correlation between bed net distribution and the level of bed 
net ownership in 2007 or the change in bed net ownership between 2001 and 2007. In any case, both correlations are high: .73 and .62 , respectively. The last three columns show data on whether the child slept under a bed net. Overall, bed net use more than doubled over this period, reaching $43 \%$. Across provinces, the correlation between the change in bed net ownership and the change in bed net use is .72. The correlation between bed net distribution 2002-07 and the level of bed net use in 2007 is .63, while the correlation between bed net distribution and the change in bed net use is .57 .

\subsubsection{Indoor Residual Spraying}

Table 6 compares data from the DHS and the NMCC on IRS by district. We use data spraying in 2006 (before the rainy season), which was the last spraying before the 2007 DHS. The table also shows urbanization rates from the 2000 census. The nine provinces fall into three groups. Four provinces, all with very low rates of urbanization, had no official spraying, and fewer than $5 \%$ of households report having received spraying. ${ }^{19}$ In three provinces, official data show $9-16 \%$ of households sprayed, and DHS data report roughly commensurate coverage. Finally, the two most highly urbanized provinces were targeted for intensive spraying: Copperbelt ( $63 \%$ of households) and Lusaka (73\%). In both provinces there is a significant shortfall between official estimates and the DHS. This is particularly severe in Lusaka, where only $29 \%$ of children in the 2007 DHS reportedly lived in sprayed structures. Figure 10 shows the rollout of spraying at the district level. The initial 5 districts targeted in 2003 were Kabwe, Kitwe, Livingstone, Lusaka and Ndola. These are urban areas, where little net distribution was happening at the time, and where spraying was considered a relatively economical option due to the relatively high population densities. The first scale-up came in 2005, with spraying extended to Chililabombwe, Chingola, Kalulushi, Luanshya, Mufulira, Chongwe, Kafue, Solwezi, Kazungula, and Mazabuka. In general, spraying was targeted to urban areas where health facilities reported high levels of malaria incidence, so that spraying is often concentrated around the health facilities reporting to the NMCC via the HMIS.

\section{Assessing the Link from Rollout to Incidence}

Ideally, we would like to be able to use data on inputs to better health (that is, preventive measures or disease treatments) and health outcomes in order to learn the efficacy of different inputs. Such an endeavor faces obvious problems with identification. Clearly, the timing and spatial distribution of health interventions are not random. Different modalities are used in different locations because health planners make optimizing choices of what will work best in a

\footnotetext{
${ }^{19}$ There was private sector spraying being done in some districts that did not overlap with government spraying until potentially 2008. The main private sector spraying without government involvement was in areas where there were small mines of various minerals (for example, Mumbwa District).
} 
given area. Similarly, the provision of resources may respond to perceived needs. For example, extra resources may be pushed to areas where health conditions have deteriorated or are forecast to deteriorate in the future. Finally, the efficiency with which health resources are provided may be correlated with other factors that directly affect health. For example, a district with an especially competent public health staff may be able to obtain additional resources, but may also have had a lower rate of disease incidence even in the absence of these additional resources ( in the field we noted that that drug supplies, record keeping and quality, take-up of new treatment guidelines and drugs, and involvement of community health volunteers and neighborhood health committees were all highly dependent on the performance of health staff at all levels of the system, and that the level of performance varied significantly). Given these program allocation mechanisms, we are only able to identify the causal effect of health interventions to the extent that there is some (measureable) randomness to the pattern by which such interventions are applied.

If there is statistical power to identify the effects of inputs to better health on health outcomes, it will generally only be in cases where these inputs deviate from the optimal plan or when inputs respond to conditions in some non-continuous fashion.

Since we do not have a formal model of optimizing choice of treatments, it is not possible to formally specify deviation from that optimal plan and use these. In this paper, we focus on the presentation and discussion of observed correlations between the rollout of different malaria control modalities and available health outcomes.

\subsection{Bed Nets}

In addition to the other statistical problems discussed above, assessment of the link from ITN distribution to health outcomes is complicated by the facts that ITNs have limited effective lifetimes, and that the length of time over which they remain effective has been changing.

\subsubsection{ITNs in the DHS}

The first measure of malaria we use in the DHS is a binary indicator that equals one if the child had a fever over the two weeks preceding the interview. The data are pooled from the 2001 and 2007 waves of the DHS; the unit of observation is a child under age five. We include dummies for individual years of age and a dummy for being in the 2007 wave. In addition, all specifications control for district fixed effects, sex, mother's age, mother's age squared, mother's education, mother's marital status, mother's employment status, urban, female household head, number of household members and household assets (electricity, radio, television, refrigerator, and bicycle). 
In the first two columns of Table 7, we use indicators for whether a household owns a bed net, and for whether the child slept under a bed net the previous night as measures of input to malaria control, respectively. In both cases, we do not think that the estimated coefficient can be interpreted structurally, because both ownership and use of the bed net are affected by disease conditions and other household characteristics related to health outcomes. In the third column, we use bed net distribution per capita as recorded by the NMCC in the district in the period between the two DHS surveys as the independent variable. The variable is zero for all 2001 observations. The coefficient is quite significant, and implies that a distribution of one net per person in the district (100\% coverage) lowers fever prevalence by about 20 percentage points. In column 4 we instrument for household ownership with per-capita distribution in the household's district (the first stage is reported in Table 8).

In columns 5 and 6 we do a placebo test, using diarrhea in the two weeks preceding the interview as a dependent variable; we use OLS in column 5 and apply the same IV strategy used in column 4 in column 6. Diarrhea is an important health outcome, but reductions in prevalence should not be related to bed net distribution. The bed nets have no significant effect.

One concern with the results in Table 7 is that, as mentioned above, the distribution of nets is not random. Since all the regressions include district fixed effects, the fact that more nets are distributed in districts with permanently higher malaria is not a concern. However if nets are distributed in response to temporary changes in malaria prevalence, our results could be biased. For example, suppose that nets are targeted to districts experiencing temporarily high malaria prevalence. In this case, our estimate would be biased to show nets being more effective than they really are. To attempt to remove this bias, in Table 9 we control for baseline fever prevalence, that is, regress the change in fever between the two DHS surveys on bed net coverage as well as the fraction of children with fevers in the two weeks prior to the 2001 DHS survey. The coefficient on baseline prevalence is slightly less than one, indicating a moderate degree of convergence over time. The coefficient on bed net distribution per capita falls by roughly half but remains significant while the coefficient on household bed nets becomes insignificant.

Finally, in Table 10 we aggregate to the level of districts and do a regression in first differences. The dependent variable is the change in fever prevalence between the two waves of the DHS. The measure of malaria control is the change in bed net ownership, in column 1, and ITN distribution in the five years prior to the survey in the other columns. The results look very similar to the individual level regressions. In particular the effect of ITN rollout falls by about half once we control for baseline fever prevalence, but remains significant.

In Table 11 we look at child mortality data in the DHS for evidence of the effects of ITNs. As in Tables 7 and 9, we report in columns 1 and 2 results in which the independent 
variable of interest is whether the household owns a bed net and whether children slept under a bed net the previous night. (Note that this latter variable applies the household in which the child was born, not the child him/herself. We cannot use the child specific use variable here since it is missing for all the deceased children). We do not interpret these estimates structurally, since there are biases that go in both directions: households that care more (or know more) about their children's health are more likely to have their children sleep under a bed net, which would yield an overestimate of the true effect. On the other hand, one might also expect some learning from the parents' side: parents who have lost one child to malaria in the last five years might be more likely to make their remaining children sleep under a net than parents who have not lost a child which would yield a selection bias going in the opposite direction. In column 3, we use district ITN coverage as the explanatory variable. The coefficient is borderline significant, but of a large magnitude (-.044). It implies that a full coverage with bed nets (one net per capita) in the years prior to the surveys lowers child mortality by 4.4 percentage points from an average baseline level of 12.7 in the 2001 survey.

One concern with the mortality regressions is that mortality covers the whole 5 years prior to the survey, while all the household level information we have (ownership and use of bed nets, assets etc) relates to the time of the survey. When restricting the analysis to the three years prior to the survey, similar results emerge; with a 1 year restriction, the sample becomes too small for identification. One last interesting finding is the negative estimate on female. This matches raw DHS data: under five mortality in 2007 was estimated at 151 for males and 124 for females.

\subsubsection{ITNs in the HMIS}

Using the HMIS, we can take advantage of much higher frequency data on disease impact and more carefully explore time variations in the program rollout relative to the DHS data. Table 12 presents descriptive statistics for our panel of HMIS data. We match malaria inpatients, malaria deaths, and non-malaria deaths, all for children under five, with data on net distribution. Since program rollout data is available only at the district level, we aggregate the facility-based HMIS data at the same level.

Table 13 shows regressions of health outcomes in a district on net distribution in the same calendar year as well as the two preceding years. The top part of the table looks at absolute numbers of cases and nets distributed; in the bottom part, cases are normalized by the under-five population, and nets are normalized by district population. Because malaria incidence peaks in the first quarter of the year, while nets are distributed throughout the year, our expectation is that the greatest impact on disease in a year should be net distribution in the previous year. Table 13 shows that this expectation holds true. The coefficient on net distribution in the previous year is always negative and significant as a predictor of malaria cases; nets in the current year are not. 
Interestingly, nets distributed two years earlier are also often insignificant as a predictor of malaria cases.

The interpretation of the coefficient on once-lagged nets in columns 2 and 3 of the top panel is as follows: 100,000 nets distributed lead to a reduction of about 900 under-five malaria inpatients and to a reduction of 25 child deaths reported at health facilities in the average district. Recall that the HMIS records only about one fourth of deaths. If we assume that the reduction in HMIS mortality in the regressions is only $25 \%$ of the true benefit, 100,000 nets mean approximately 100 child lives saved.

The lower part of the table, where cases and nets are scaled by population, yields estimates similar in magnitude. Full coverage of bed nets (one per person) leads lowers malaria inpatients by 26 cases per 1000 , which is a reduction of $35 \%$ relative to the mean. Similarly, full bed net coverage lowers malaria deaths per 1000 by a factor of 0.8 , which corresponds to a reduction of $42 \%$ relative to the mean.

\subsection{Indoor Residual Spraying}

The manner in which IRS was rolled out suggests that it might be a good candidate for econometrically identifying the effects of the program on disease outcomes. In the initial design of the malaria initiative, IRS was to be restricted to only areas of very high population density. The scope of IRS was expanded in discrete jumps in 2008. Further, unlike bed nets, IRS must be re-applied each year to be effective. IRS is generally conducted at the end of the calendar year, before the onset of the rainy season when malaria is high.

\subsubsection{IRS in the DHS}

Table 14 shows regressions of child fever on spraying, similar to the regressions for bed nets reported in Table 7. When spraying is included alone on the right hand side, the estimated coefficient is positive, implying that districts that were sprayed in 2007 had a worse time trend for malaria (i.e. slower decline in malaria over time) than those that were not sprayed in that year. This result is driven by a strong negative correlation between the initial fever burden and the rollout of the spraying. By the time of the 2007 DHS, spraying was done in 15 districts, which on average had a fever prevalence of $37 \%$ in 2001 , significantly below the national average of $45 \%$ in that year. In 2007 , the average fever prevalence in the spraying target areas was actually slightly above the non-spraying areas. This result looks the same when we run the regressions at the individual level (households reporting whether or not they have been sprayed over the 12 months preceding the interview) as shown in column 2. 
To minimize the potential convergence bias we focus on the 2007 survey only in columns 3 and 4. In column 3, we use spraying at the household level only; in column 4, we take the fraction of households sprayed within the cluster (typically 15 households with children per cluster) as explanatory variable. The coefficient becomes negative, but is not significant. Within a given district, targeted households and clusters appear to have similar fever prevalence rates to non-targeted ones.

We are not quite sure what to make out of this result; if the numbers are correct, it could either be that spraying misses its target (people get infected outside, or spraying is done before the rain and then washed away), or, alternatively, that households that don't get spraying have lower risk or more actively engage in other unobserved preventive measures.

\subsubsection{IRS in the HMIS}

As with the ITN analysis, the use of the HMIS has the main advantage of offering higher frequency data when it comes to evaluating the disease impact of the IRS spraying. Given that spraying loses its protective effect within about a year, close to all spraying in Zambia arranged through the NMCP is done in the last quarter of the each year when the rains start and mosquito populations rapidly re-emerge after the dry season. Under ideal conditions, IRS spraying is supposed to protect household members throughout the rainy seasons, and to be repeated at the end of each year with the new rainfalls.

In Table $15 \mathrm{~A}$, we try to identify the effects of IRS spraying on the levels of malaria inpatients, malaria deaths and deaths due to other causes with a simple IRS spraying target dummy. The IRS target dummy variable equals 1 if the district was in the spraying program in a given year, and is zero otherwise. As Figure 10 shows, the rollout of the IRS implemented by the NMCP spraying was incremental; any district enrolled in the program since 2003 has been receiving spraying in all subsequent years. In columns 1-3, we regress health outcomes on spraying without controlling for the contemporaneous net distribution. The effects of IRS spraying on malaria inpatients and malaria deaths are negative, but only marginally significant. The estimated coefficient in column 2 implies that being a target district is associated with 22.5 fewer malaria deaths per year and district. Once we add controls for bed net rollout in columns 46 , the estimated effects on the number of under-5 malaria inpatients and deaths become larger and more significant. A simple comparison of the estimated coefficients in column 5 implies that the effect of becoming a target for spraying is comparable to the distribution of 100,000 nets in the preceding year in the average district.

The results become much weaker, however, when we express patients and mortality numbers in population terms, and regress disease burden per capita on per capita measures of bed net and spraying rollout in Table $15 \mathrm{~B}$. While the coefficient on bed net distribution remains 
highly significant (and similar in magnitude to the ITN regressions where we do not control for spraying), the spraying coverage does not appear to have any effect on the number of malaria patients per 1,000 children under 5 in this specification. The estimated effect on under-5 malaria deaths (column 5) is just shy of significance. The relative magnitude of the coefficients estimated in column 5 implies that providing full spraying coverage has about half the effect of providing full net coverage.

Overall, the estimated effects of the IRS campaign in the HMIS are surprisingly weak given the design of the spraying rollout. As Figure 11 illustrates, the IRS campaign is generally directly focused around health facilities. Trying to maximize the impact of the campaign, programs generally concentrate their efforts to the (catchment) areas directly surrounding facilities reporting a high malaria caseload in the given period. Given the stochasticity of local malaria incidence, particularly high incidence years in a particular area are likely to be followed by more moderate years, so that the simple difference-in-difference model estimated above should lead to an overestimation of the true effect. The fact that the effects are weak even in the HMIS is thus rather puzzling, but in our view consistent with the rather weak evidence on spraying emerging from the DHS analysis.

\section{Conclusions}

\subsection{Future directions for research}

As mentioned in the Introduction, the current paper is part of a larger project in which the authors hope to use the Zambia malaria initiative to better understand the economic effects of malaria. It is worth stepping back for a moment to see why the Zambian experience is particularly useful in this regard. Discussion in the policy community regarding the relative priority of improving health in developing countries often points to the economic benefits accruing from better health as an important secondary justification complementary to the direct humanitarian and health benefits associated with related programs. The question of how disease affects economic growth is well established in the literature. Much of the discussion of the economic effects of malaria among policy makers, for example, cites estimates from the work of Gallup and Sachs (2001). Trying to estimate the effect of health on economic outcomes runs into serious identification problems, however. Omitted factors that affect health may affect income directly, or health may respond directly to improvements in income. The standard solution for such an identification problem is to find instrumental variables that directly affect health. These instruments could be some purely exogenous factor or possibly the result of some discontinuous response of health inputs to local conditions. For example, Acemoglu and Johnson (2007) use variations in technological progress in controlling different diseases during the post World War II period to instrument for health changes at the national level. Even though malaria is viewed as one of the most economically important diseases, most recent studies of its 
economic effects have had to rely on data from episodes of malaria eradication in South Asia and Latin America that took place half a century ago (see Lucas (2010), and Bleakley (2007)). As discussed above, the large scaling up of resources devoted to malaria control in Zambia was not primarily the result of factors on the ground in the country itself. Rather, developments on the world stage, including the development of new technology and a new alignment of priorities within the development community, led to Zambia being chosen as a test case for the possibility of rapidly scaled up malaria control. Thus, at the aggregate level, the timing of the reduction in malaria in Zambia may be viewed as largely exogenous. Of course, Zambia was chosen as the first country to receive such intensive support and treatment because it was viewed as having the institutional capacity to succeed, and the same factors that were expected to lead to success against malaria might have been expected to have independent economic effects, so the identification is not perfect. Nonetheless, the suddenness with which resources were applied suggests that reasonable identification may be possible. Beyond the inferences that can be drawn from developments at the national level, our hope is that additional identification can be achieved by looking at the manner in which the campaign against malaria was rolled out within Zambia.

Some of the issues that we hope to investigate in later work include:

\section{Fertility}

A substantial literature discusses the link between changes in mortality and changes in fertility. In particular, it is often argued that declining infant and child mortality initially leads to a rise in the total fertility rate, as actual deaths fall short of expectations, but that in the long run TFR declines because of reduced uncertainty. In the case of malaria, there is an additional set of considerations, because the disease works to lower fecundity directly (Lucas, 2010). Figures from the DHS early release show that TFR in Zambia rose from 5.9 to 6.2 over the period 20022007 (6.9 to 7.5 in rural areas, while urban TFR was flat at 4.0). The period between DHS surveys corresponds well to the period of rollout of the malaria program.

\section{Productivity}

One way in which malaria affects economic outcomes is by directly lowering the labor input of workers, both through absenteeism and reduced physical capacity due to anemia. There are some cases where we hope to observe directly the productivity effects of malaria control. We are working on obtaining data from Zambia Sugar, the country's largest producer, which is located in the Mazabuka district. Zambia Sugar undertook a private eradication effort that predated the national effort by several years. Malaria morbidity has traditionally been quite high among cane cutters, who must work in swampy conditions. We hope to obtain data on changes 
in absenteeism over time (this data was actually collected once already, but was subsequently lost).

\section{Education}

Many economists have stressed malaria's effect on educational attainment as an important channel through which the disease affects economic outcomes. By matching data from Zambia's educational statistics system on grade progress, and dropout rates to data on the rollout of the anti-malaria initiative, we hope to investigate how much health improvements have lead to an increase in educational attainment.

\subsection{Sustainability and Further Progress}

The progress already made against malaria and other sources of premature mortality in Zambia represents a major humanitarian success. One issue raised by progress so far is whether it will be possible to finish the job, and reduce malaria incidence to near zero. The history of anti-malaria campaigns in the years after World War II contains several episodes in which malaria was substantially eliminated. Eradication is also the NMCC's eventual goal, even if it isn't possible in the short term. There are currently some discussions on pilot projects in a few districts to do a massive test and treat campaign to reduce parasitemia to near zero. Zambia was chosen as a test country for scale-up for multiple reasons: reason-one important reason was that the institutional capacity, good governance, and political will existed to make use of the resources. However, it is also the case that the climate is favorable to eventual complete eradication because of the cold winters that ensure mosquito populations are reduced to nearzero for at least some period annually.

Until malaria is completely eliminated in the country, however, a serious concern remains regardingthe sustainability of gains achieved so far. As discussed above, Zambia has already been through an episode in which significant progress against malaria was followed by a resurgence of the disease. Similarly, in Zambia's neighbor Zimbabwe, malaria was almost completely eradicated, but the political environment led to the end of an effective malaria control regime and the disease has subsequently returned to epidemic levels. In the current Zambian environment, disease vectors remain present and a significant number of humans continue to host the disease. This means that unlike places where eradication has been complete, there is always the potential for a rapid resurgence, which could be all the more devastating as cohorts with lower acquired immunity age through the population. Maintaining the low current level of malaria mortality and morbidity will thus require continued application of inputs at near the current level. The life-span of a bed net averages three years if properly treated, so maintaining a ratio of one net for every two persons will require the distribution of approximately 2 million 
nets per year. Indoor spraying must be repeated annually. Thus there will be only limited scope for a reduction in spending and effort devoted to malaria control. 


\section{References}

Bleakley, Hoyt. 2010. Malaria eradication in the Americas: A retrospective analysis of childhood exposure. American Economic Journal: Applied Economics, 2 (2) : 1-45.

Bleakley, Hoyt. 2007. Disease and development: Evidence from hookworm eradication in the American South. Quarterly Journal of Economics, 122(1) : 73-117.

Chanda, Pascalina, Felix Masiye, Bona M. Chitah, Naawa Sipilanyambe, Moonga Hawela, Patrick Banda and Tuoyo Okorosobo. 2007. A cost-effectiveness analysis of artemetherlumefantrine for treatment of uncomplicated malaria in Zambia. Malaria Journal, 6 (21).

Gallup, John L. and Jeffrey D. Sachs. 2001. The economic burden of malaria. American Journal of Tropical Medicine and Hygiene, 64(1, 2)S: 85-96.

Government of Zambia, Central Statistical Office, et al. Zambia Demographic and Health Survey 2001-2002 Lusaka: February 2003.

Government of Zambia, Central Statistical Office, et al. 2009. Zambia Demographic and Health Survey 2007. Lusaka. Available online:

http://www.measuredhs.com/pubs/pdf/FR211/FR211[revised-05-12-2009].pdf.

Government of Zambia, Central Statistical office. 2003. 2000 Census of Population and Housing. Lusaka. Available online: http://www.zamstats.gov.zm/media/sum_rpt.pdf.

Government of Zambia, Ministry of Health. 2008 National Malaria Control Action Plan: Actions for Scale-up for Impact on Malaria in Zambia. Lusaka. Available online: http://nmcc.org.zm/files/2008ZambiaNMCPActionPlan-5-20.pdf .

Government of Zambia, Ministry of Health. 2007 National Malaria Control Action Plan: Actions for Scale-up for Impact on Malaria in Zambia. Lusaka.

Government of Zambia, Ministry of Health. 2006 National Malaria Control Action Plan: Actions for Scale-up for Impact on Malaria in Zambia. Lusaka.

Government of Zambia, Ministry of Health. 2007. A Guide on Performance Assessment and Technical Support. Lusaka. Available online: http://pdf.usaid.gov/pdf_docs/PNADR331.pdf.

Government of Zambia, Ministry of Health. A Roadmap for Impact on Malaria in Zambia: A 5 Year Strategic Plan, 2006-2010. Lusaka. 
Government of Zambia. Estimates of Revenue and Expenditure: Activity-Based Budget 2008. Lusaka.

Government of Zambia, Ministry of Health. Guidelines on the Distribution and Utilization of Insecticide-Treated Nets for Malaria Prevention and Control. Lusaka: November 2008.

Government of Zambia, Ministry of Health. 2008. Health Facilities in Zambia: A Listing of Health Facilities According to Level and Location for 2008. Lusaka..

Government of Zambia, Ministry of Health. Health Management Information System. Lusaka.

Government of Zambia, Ministry of Health. 2005. National Health Strategic Plan 2006-2010. Lusaka.

Government of Zambia, Ministry of Health, et al. 2006. Zambia National Malaria Indicator Survey 2006. Lusaka.

Government of Zambia, Ministry of Health. 2009. Zambia National Malaria Indicator Survey 2008. Lusaka.

Hamer, Davidson H., Micky Ndhlovu, Dejan Zurovac, Matthew Fox, Kojo Yeboah-Antwi, Pascalina Chanda, Naawa Sipilinyambe, Jonathan L. Simon, and Robert W. Snow. 2007. Improved diagnostic testing and malaria treatment practices in Zambia. The Journal of the American Medical Association, 297 (20): 2227-2231.

Lubell, Yoel, Hugh Reyburn, Hilda Mbakilwa, Rose Mwangi, Semkini Chonya, Christopher J.M. Whitty, and Anne Mills. 2008. The impact of response to the results of diagnostic tests for malaria: Cost-benefit analysis. British Medical Journal, 336(7637): 202-205.

Lucas, Adrienne M. 2010. Malaria eradication and educational attainment: Evidence from Paraguay and Sri Lanka. American Economic Journal: Applied Economics, 2(2): 46-71.

Lucas, Adrienne. 2010. The impact of malaria eradication on fertility. Wellesley College Working Paper.

Packard, Randall M. 2007. The Making of a Tropical Disease: A Short History of Malaria. Baltimore, MD: Johns Hopkins University Press.

Rolland Estelle., Francesco Checchi, Loretxu Pinoges, Suna Balkan, Jean-Paul Guthmann, and Philippe J. Guerin. 2006. "Operational Response to Malaria Epidemics: Are Rapid Diagnostic Tests Cost-effective? Tropical Medicine and International Health, 11(4): 398-408. 
Sipilanyambe, Naawa., Jonathan L. Simon, Pascalina Chanda, Peter Olumese, Robert W. Snow, and Davidson H. Hamer. 2008. "From Chloroquine to Artemether-Lumefantrine: The Process of Drug Policy Change in Zambia." Malaria Journal, 7(25).

Steketee, Richard W., Naawa Sipilanyambe, John Chimumbwa, James J. Banda, Abdirahuman Mohamed, John Miller, Surprotik Basu, Simon K. Miti, and Carlos C. Campbell. 2008. National malaria control and scaling up for impact: The Zambia experience through 2006." American Journal of Tropical Medicine and Hygiene, 79(1): 45-52.

World Health Organization. 2007. Malaria Rapid Diagnostic Tests: Assessing Cost-Effectiveness of Diagnosis. Available online:

http://www.wpro.who.int/sites/rdt/using_rdts/assessing_cost_effectiveness.htm.

Zurovac, Dejan, Mickey Ndhlovu, Nawa Sipilanyambe, Pascalina Chanda, Davidson H. Hamer, Jon L. Simon, and Robert W. Snow. 2007. "Paediatric Malaria Case-Management With Artemether-Lumefantrine in Zambia: A Repeat Cross-Sectional Study." Malaria Journal, 6 (31). Available online: http://www.malariajournal.com/content/6/1/31. 
Table 1: National Level HMIS Data Sets, Before and After Malaria Data Review Workshops

\begin{tabular}{|c|c|c|c|c|}
\hline & $\begin{array}{l}\text { Pre-workshop } \\
\text { data set }^{(1)}\end{array}$ & Additions $^{(2)}$ & Edits $^{(3)}$ & $\begin{array}{r}\text { Post-workshop } \\
\text { data set }^{(4)}\end{array}$ \\
\hline Health facilities & 1,473 & 28 & & 1,501 \\
\hline Quarterly reports & 43,455 & 1,901 & & 45,356 \\
\hline Outpatient & & & & \\
\hline observations & $2,066,964$ & 76,036 & 32,510 & $2,143,000$ \\
\hline Inpatient observations & 743,650 & 23,041 & 8,638 & 766,691 \\
\hline Death observations & 365,589 & 9,132 & 2,142 & 374,721 \\
\hline
\end{tabular}


Table 2: Inpatient and Mortality Data from the HMIS

\begin{tabular}{|c|c|c|c|c|c|c|c|c|}
\hline & \multicolumn{4}{|c|}{ All Facilities } & \multicolumn{4}{|c|}{ Always Reporting Facilities } \\
\hline & $\begin{array}{l}\text { Malaria } \\
\text { in- } \\
\text { patients } \\
\text { under age } \\
5\end{array}$ & $\begin{array}{l}\text { Malaria } \\
\text { in- } \\
\text { patient } \\
\text { deaths } \\
\text { under } \\
\text { age } 5\end{array}$ & $\begin{array}{l}\text { Malaria in- } \\
\text { patients } \\
\text { age } 5 \text { and } \\
\text { over }\end{array}$ & $\begin{array}{l}\text { Malaria } \\
\text { in- } \\
\text { patient } \\
\text { deaths } \\
\text { age } 5 \\
\text { and over }\end{array}$ & $\begin{array}{l}\text { Malaria } \\
\text { in- } \\
\text { patients } \\
\text { under } \\
\text { age } 5\end{array}$ & $\begin{array}{l}\text { Malaria } \\
\text { in- } \\
\text { patient } \\
\text { deaths } \\
\text { under } \\
\text { age } 5\end{array}$ & $\begin{array}{l}\text { Malaria } \\
\text { in- } \\
\text { patients } \\
\text { age } 5 \\
\text { and } \\
\text { over }\end{array}$ & $\begin{array}{l}\text { Malaria } \\
\text { in- } \\
\text { patient } \\
\text { deaths } \\
\text { age } 5 \\
\text { and over }\end{array}$ \\
\hline 2000 & 134,516 & 5,039 & 96,569 & 3,882 & 65,457 & 2,223 & 47,818 & 1,745 \\
\hline 2001 & 167,814 & 5,598 & 117,214 & 4,352 & 75,308 & 2,619 & 51,158 & 1,885 \\
\hline 2002 & 162,760 & 4,937 & 114,759 & 4,530 & 71,440 & 2,117 & 48,857 & 1,740 \\
\hline 2003 & 167,919 & 4,808 & 124,665 & 4,727 & 72,718 & 1,919 & 51,079 & 1,895 \\
\hline 2004 & 136,623 & 4,056 & 99,938 & 4,352 & 56,524 & 1,626 & 40,159 & 1,572 \\
\hline 2005 & 139,808 & 3,489 & 96,014 & 3,979 & 56,557 & 1,357 & 38,952 & 1,629 \\
\hline 2006 & 141,312 & 3,235 & 96,977 & 3,096 & 56,251 & 1,295 & 40,056 & 1,383 \\
\hline 2007 & 119,618 & 2,684 & 83,599 & 2,356 & 50,092 & 1,160 & 34,703 & 1,070 \\
\hline \multirow[t]{3}{*}{2008} & 69,637 & 1,680 & 56,693 & 1,566 & 32,004 & 861 & 26,972 & 807 \\
\hline & \multicolumn{4}{|c|}{ All Facilities } & \multicolumn{4}{|c|}{ Always Reporting Facilities } \\
\hline & $\begin{array}{l}\text { Non- } \\
\text { Malaria } \\
\text { in- } \\
\text { patients } \\
\text { under age } \\
5\end{array}$ & $\begin{array}{l}\text { Non- } \\
\text { Malaria } \\
\text { in- } \\
\text { patient } \\
\text { deaths } \\
\text { under } \\
\text { age } 5\end{array}$ & $\begin{array}{l}\text { Non- } \\
\text { malaria in- } \\
\text { patients } \\
\text { age } 5 \text { and } \\
\text { over }\end{array}$ & $\begin{array}{l}\text { Non- } \\
\text { malaria } \\
\text { in- } \\
\text { patient } \\
\text { deaths } \\
\text { age } 5 \\
\text { and over }\end{array}$ & $\begin{array}{l}\text { Non- } \\
\text { Malaria } \\
\text { in- } \\
\text { patients } \\
\text { under } \\
\text { age } 5\end{array}$ & $\begin{array}{l}\text { Non- } \\
\text { Malaria } \\
\text { in- } \\
\text { patient } \\
\text { deaths } \\
\text { under } \\
\text { age } 5\end{array}$ & $\begin{array}{l}\text { Non- } \\
\text { malaria } \\
\text { in- } \\
\text { patients } \\
\text { age } 5 \\
\text { and } \\
\text { over }\end{array}$ & $\begin{array}{l}\text { Non- } \\
\text { malaria } \\
\text { in- } \\
\text { patient } \\
\text { deaths } \\
\text { age } 5 \\
\text { and over }\end{array}$ \\
\hline 2000 & 148,116 & 11,684 & 225,018 & 15,713 & 70,757 & 5,644 & 105,645 & 7,507 \\
\hline 2001 & 183,368 & 12,103 & 248,121 & 16,699 & 75,893 & 5,380 & 109,316 & 7,426 \\
\hline 2002 & 169,333 & 12,090 & 287,986 & 18,913 & 67,356 & 4,872 & 116,814 & 7,538 \\
\hline 2003 & 172,021 & 11,224 & 286,737 & 19,758 & 70,220 & 4,618 & 117,027 & 8,401 \\
\hline 2004 & 137,414 & 9,810 & 280,107 & 20,967 & 57,332 & 3,906 & 111,896 & 8,033 \\
\hline 2005 & 156,309 & 9,641 & 298,237 & 20,709 & 68,430 & 3,842 & 120,392 & 8,064 \\
\hline 2006 & 152,304 & 9,315 & 291,504 & 20,052 & 65,545 & 3,568 & 117,190 & 7,708 \\
\hline 2007 & 157,118 & 9,816 & 297,832 & 17,652 & 69,290 & 4,477 & 119,387 & 6,939 \\
\hline 2008 & 124,813 & 6,423 & 231,925 & 12,887 & 68,627 & 3,269 & 112,440 & 6,193 \\
\hline
\end{tabular}


Table 3: Seasonality and Changes over Time

\begin{tabular}{|c|c|c|c|c|}
\hline & \multicolumn{2}{|c|}{$\begin{array}{c}\text { Under } 5 \text { Deaths per } 1000-\text { All } \\
\text { Causes }\end{array}$} & \multicolumn{2}{|c|}{$\begin{array}{c}\text { Under } 5 \text { Deaths per } 1000 \text { - } \\
\text { Malaria }\end{array}$} \\
\hline & (1) & (2) & (3) & (4) \\
\hline Second quarter & $\begin{array}{c}-0.326 * * * \\
(0.0486)\end{array}$ & $\begin{array}{c}-0.324 * * * \\
(0.0652)\end{array}$ & $\begin{array}{c}-0.136 * * * \\
(0.0202)\end{array}$ & $\begin{array}{c}-0.111 * * * \\
(0.0270)\end{array}$ \\
\hline Third quarter & $\begin{array}{c}-0.726 * * * \\
(0.0488)\end{array}$ & $\begin{array}{c}-0.584 * * * \\
(0.0656)\end{array}$ & $\begin{array}{c}-0.360 * * * \\
(0.0203)\end{array}$ & $\begin{array}{c}-0.258 * * * \\
(0.0271)\end{array}$ \\
\hline Fourth quarter & $\begin{array}{l}-0.431 * * * \\
(0.0488)\end{array}$ & $\begin{array}{c}-0.318 * * * \\
(0.0657)\end{array}$ & $\begin{array}{l}-0.235 * * * \\
(0.0203)\end{array}$ & $\begin{array}{l}-0.152 * * * \\
(0.0272)\end{array}$ \\
\hline Pre 2004 & & $\begin{array}{l}1.186 * * * \\
(0.0869)\end{array}$ & & $\begin{array}{l}0.522 * * * \\
(0.0359)\end{array}$ \\
\hline Second Q. * pre & & $\begin{array}{l}-0.00536 \\
(0.0976)\end{array}$ & & $\begin{array}{l}-0.0563 \\
(0.0404)\end{array}$ \\
\hline Third Q. * pre & & $\begin{array}{c}-0.317 * * * \\
(0.0978)\end{array}$ & & $\begin{array}{l}-0.227 * * * \\
(0.0405)\end{array}$ \\
\hline Fourth Q. * pre & & $\begin{array}{l}-0.251 * * \\
(0.0978)\end{array}$ & & $\begin{array}{l}-0.185 * * * \\
(0.0405)\end{array}$ \\
\hline Year 2001 & $\begin{array}{c}0.0697 \\
(0.0728)\end{array}$ & $\begin{array}{c}0.0697 \\
(0.0726)\end{array}$ & $\begin{array}{c}0.0438 \\
(0.0302)\end{array}$ & $\begin{array}{c}0.0438 \\
(0.0300)\end{array}$ \\
\hline Year 2002 & $\begin{array}{l}-0.148 * * \\
(0.0728)\end{array}$ & $\begin{array}{l}-0.149 * * \\
(0.0726)\end{array}$ & $\begin{array}{c}-0.0830 * * * \\
(0.0303)\end{array}$ & $\begin{array}{c}-0.0832 * * * \\
(0.0300)\end{array}$ \\
\hline Year 2003 & $\begin{array}{c}-0.346 * * * \\
(0.0728)\end{array}$ & $\begin{array}{c}-0.346 * * * \\
(0.0726)\end{array}$ & $\begin{array}{c}-0.121 * * * \\
(0.0302)\end{array}$ & $\begin{array}{c}-0.121 * * * \\
(0.0300)\end{array}$ \\
\hline Year 2004 & $\begin{array}{c}-0.733 * * * \\
(0.0728)\end{array}$ & $\begin{array}{l}0.608 * * * \\
(0.0744)\end{array}$ & $\begin{array}{c}-0.255^{* * *} \\
(0.0302)\end{array}$ & $\begin{array}{c}0.249 * * * \\
(0.0308)\end{array}$ \\
\hline Year 2005 & $\begin{array}{c}-0.808 * * * \\
(0.0728)\end{array}$ & $\begin{array}{c}0.534 * * * \\
(0.0744)\end{array}$ & $\begin{array}{c}-0.294 * * * \\
(0.0302)\end{array}$ & $\begin{array}{c}0.209 * * * \\
(0.0308)\end{array}$ \\
\hline Year 2006 & $\begin{array}{c}-0.931 * * * \\
(0.0728)\end{array}$ & $\begin{array}{c}0.411 * * * \\
(0.0745)\end{array}$ & $\begin{array}{c}-0.330 * * * \\
(0.0303)\end{array}$ & $\begin{array}{c}0.174 * * * \\
(0.0308)\end{array}$ \\
\hline Year 2007 & $\begin{array}{c}-1.008 * * * \\
(0.0730)\end{array}$ & $\begin{array}{c}0.334 * * * \\
(0.0746)\end{array}$ & $\begin{array}{c}-0.384 * * * \\
(0.0303)\end{array}$ & $\begin{array}{c}0.120 * * * \\
(0.0308)\end{array}$ \\
\hline Year 2008 & $\begin{array}{c}-1.344 * * * \\
(0.0746)\end{array}$ & & $\begin{array}{c}-0.505 * * * \\
(0.0310)\end{array}$ & \\
\hline Constant & $\begin{array}{c}2.584 * * * \\
(0.0595)\end{array}$ & $\begin{array}{l}1.178 * * * \\
(0.0668)\end{array}$ & $\begin{array}{l}0.872 * * * \\
(0.0247)\end{array}$ & $\begin{array}{c}0.316 * * * \\
(0.0276)\end{array}$ \\
\hline
\end{tabular}




\begin{tabular}{lllll} 
Observations & 2562 & 2562 & 2562 & 2562 \\
R-squared & 0.550 & 0.554 & 0.417 & 0.426 \\
\hline
\end{tabular}

Standard errors in parentheses. All estimates include district fixed effects.

$* * * \mathrm{p}<0.01, * * \mathrm{p}<0.05, * \mathrm{p}<0.1$

Data source: HMIS 
Table 4: Rollout Data at the National Level

\begin{tabular}{rrrr}
\hline \hline & $\begin{array}{r}\text { Number of bed nets } \\
\text { distributed }\end{array}$ & $\begin{array}{r}\text { Population covered by } \\
\text { spraying }\end{array}$ & RDTs Distributed \\
2002 & 112,020 & - & 0 \\
2003 & 557,071 & 324,137 & 0 \\
2004 & 176,082 & 679,582 & 0 \\
2005 & 516,999 & $1,163,802$ & 172,257 \\
2006 & $1,163,113$ & $2,836,778$ & 25,700 \\
2007 & $2,446,102$ & $3,286,514$ & 243,600 \\
2008 & 964,748 & $5,558,822$ & $2,015,500$ \\
\hline
\end{tabular}

Source: NMCC. 
Table 5: ITN Distribution, Ownership, and Use

\begin{tabular}{|c|c|c|c|c|c|c|c|c|}
\hline & $\begin{array}{l}\text { Total nets } \\
\text { distributed } \\
\text { between } \\
2001 \text { and } \\
2007 \text { DHS }^{\text {a) }}\end{array}$ & $\begin{array}{c}\text { Nets } \\
\text { distributed } \\
\text { per person } \\
\text { between } 2001 \\
\text { and } 2007 \\
\mathrm{DHS}^{\mathrm{a}), \mathrm{c})}\end{array}$ & $\begin{array}{l}\text { Percentage of } \\
\text { children in } \\
\text { household } \\
\text { owning at } \\
\text { least one net } \\
2001^{\text {b) }}\end{array}$ & $\begin{array}{l}\text { Percentage of } \\
\text { children in } \\
\text { households } \\
\text { owning at } \\
\text { least one net } \\
2007^{\text {b) }}\end{array}$ & $\begin{array}{l}\text { Change in } \\
\text { ownership } \\
\text { DHS } \\
2001 \text { - } \\
\text { DHS } \\
2007^{\text {b) }}\end{array}$ & $\begin{array}{l}\text { Percentage } \\
\text { of children } \\
\text { sleeping } \\
\text { under net } \\
2001^{\text {b) }}\end{array}$ & $\begin{array}{l}\text { Percentage } \\
\text { of children } \\
\text { sleeping } \\
\text { under net } \\
2007^{\text {b) }}\end{array}$ & $\begin{array}{c}\text { Change } \\
\text { in child } \\
\text { net use } \\
\text { DHS } \\
2001 \text { to } \\
\text { DHS } \\
2007^{\text {b) }} \\
\end{array}$ \\
\hline Central & 188,405 & 0.15 & 0.23 & 0.68 & 0.45 & 0.13 & 0.37 & 0.25 \\
\hline Copperbelt & 224,425 & 0.12 & 0.31 & 0.74 & 0.43 & 0.20 & 0.43 & 0.23 \\
\hline Eastern & 206,439 & 0.12 & 0.25 & 0.71 & 0.46 & 0.20 & 0.37 & 0.17 \\
\hline Luapula & 417,351 & 0.43 & 0.36 & 0.86 & 0.50 & 0.31 & 0.74 & 0.42 \\
\hline Lusaka & 264,591 & 0.16 & 0.31 & 0.68 & 0.37 & 0.20 & 0.30 & 0.10 \\
\hline Northern & 244,078 & 0.15 & 0.21 & 0.57 & 0.36 & 0.17 & 0.41 & 0.24 \\
\hline \multicolumn{9}{|l|}{ North- } \\
\hline Western & 290,202 & 0.39 & 0.36 & 0.73 & 0.38 & 0.27 & 0.43 & 0.16 \\
\hline Southern & 342,484 & 0.22 & 0.18 & 0.60 & 0.42 & 0.10 & 0.25 & 0.16 \\
\hline Western & 598,199 & 0.64 & 0.32 & 0.87 & 0.55 & 0.22 & 0.55 & 0.33 \\
\hline Total & 2,776,174 & 0.26 & 0.28 & 0.72 & 0.43 & 0.20 & 0.43 & 0.23 \\
\hline
\end{tabular}

urcSource: a) NMCC b) Zambia DHS $(2001,2007)$ c) Central Statistical Office for population estimates. 
Table 6: IRS Coverage 2007 and Self-Reported Coverage

\begin{tabular}{lccc}
\hline Province & $\begin{array}{c}\text { Fraction of population } \\
\text { officially covered by } \\
\text { spraying in 2006 }\end{array}$ & $\begin{array}{c}\text { Percentage of children in } \\
\text { 2007 DHS living in } \\
\text { sprayed households }\end{array}$ & Urbanization \\
Central & 0.12 & 0.12 & $(2000)$ \\
Copperbelt & 0.63 & 0.41 & 0.24 \\
Eastern & 0.00 & 0.02 & 0.78 \\
Luapula & 0.00 & 0.01 & 0.09 \\
Lusaka & 0.73 & 0.29 & 0.13 \\
Northern & 0.00 & 0.04 & 0.82 \\
North- & & & 0.14 \\
Western & 0.09 & 0.14 & 0.12 \\
Southern & 0.16 & 0.13 & 0.21 \\
Western & 0.00 & 0.02 & 0.12 \\
\hline
\end{tabular}

Sources: Central Statistical Office, NMCC, DHS (2007) 
Table 7: Bed Nets, Child Fever and Child Diarrhea, DHS

\begin{tabular}{|c|c|c|c|c|c|c|}
\hline \multirow[t]{2}{*}{ Dependent variable } & \multicolumn{4}{|c|}{ Child had fever over last two weeks } & \multicolumn{2}{|c|}{ Diarrhea } \\
\hline & (1) & (2) & (3) & (4) & (5) & (6) \\
\hline \multirow[t]{3}{*}{ Household owns net } & $-.0213^{*}$ & & & - & & -0.124 \\
\hline & & & & $0.921 * * *$ & & \\
\hline & $(0.0111)$ & & & $(0.267)$ & & $(0.255)$ \\
\hline \multirow[t]{2}{*}{$\begin{array}{l}\text { Child slept under } \\
\text { net }\end{array}$} & & -0.0106 & & & & \\
\hline & & $(0.0110)$ & & & & \\
\hline \multicolumn{2}{|l|}{ Bed net distribution pc } & & $\begin{array}{c}-0.209^{* * *} \\
(0.0487)\end{array}$ & & $\begin{array}{l}-0.0286 \\
(0.0703)\end{array}$ & \\
\hline \multirow[t]{2}{*}{ Child age 1} & $0.0639 * * *$ & $0.0641 * * *$ & $0.0648 * * *$ & $\begin{array}{c}0.0672 * * \\
*\end{array}$ & $0.181 * * *$ & $\begin{array}{c}0.181^{* *} \\
*\end{array}$ \\
\hline & $(0.0122)$ & $(0.0122)$ & $(0.0122)$ & $(0.0154)$ & $(0.0252)$ & $(0.0315)$ \\
\hline Child age 2 & $\begin{array}{c}0.0142 \\
(0.0132)\end{array}$ & $\begin{array}{c}0.0150 \\
(0.0134)\end{array}$ & $\begin{array}{c}0.0150 \\
(0.0132)\end{array}$ & $\begin{array}{l}0.00604 \\
(0.0150)\end{array}$ & $\begin{array}{l}-0.0307 \\
(0.0252)\end{array}$ & $\begin{array}{l}-0.0319 \\
(0.0297)\end{array}$ \\
\hline \multirow[t]{3}{*}{ Child age 3} & $-0.0728 * * *$ & - & - & - & - & - \\
\hline & & $0.0730 * * *$ & $0.0713 * * *$ & $\begin{array}{c}0.0798^{* *} \\
*\end{array}$ & $0.195 * * *$ & $\begin{array}{c}0.196^{* *} \\
*\end{array}$ \\
\hline & $(0.0125)$ & $(0.0127)$ & $(0.0125)$ & $(0.0154)$ & $(0.0247)$ & $(0.0262)$ \\
\hline \multirow[t]{3}{*}{ Child age 4} & $-0.121 * * *$ & $-0.120 * * *$ & $-0.121 * * *$ & - & - & - \\
\hline & & & & $0.122 * * *$ & $0.275 * * *$ & $\begin{array}{c}0.275^{* *} \\
*\end{array}$ \\
\hline & $(0.0127)$ & $(0.0129)$ & $(0.0127)$ & $(0.0159)$ & $(0.0216)$ & $(0.0236)$ \\
\hline \multirow[t]{3}{*}{$2^{\text {nd }}$ wave dummy } & $-0.243^{* * *}$ & $-0.250 * * *$ & $-0.197 * * *$ & 0.101 & - & -0.0335 \\
\hline & & & & & $\begin{array}{c}0.0736^{* *} \\
*\end{array}$ & \\
\hline & $(0.0115)$ & $(0.0109)$ & $(0.0169)$ & $(0.107)$ & $(0.0257)$ & $(0.0967)$ \\
\hline \multirow[t]{2}{*}{ Constant } & $0.546 * * *$ & $0.548 * * *$ & $0.548 * * *$ & $0.406^{* * *}$ & $0.735 * * *$ & $\begin{array}{c}0.773^{* *} \\
*\end{array}$ \\
\hline & $(0.0752)$ & $(0.0759)$ & $(0.0749)$ & $(0.117)$ & $(0.138)$ & $(0.196)$ \\
\hline Observations & 11193 & 11027 & 11193 & 11193 & 11187 & 11187 \\
\hline R-squared & 0.129 & 0.128 & 0.131 & -0.513 & 0.065 & 0.063 \\
\hline
\end{tabular}

Notes: All specifications control for district fixed effects, sex, mother's age, mother's age squared, mother's education, mother's marital status, mother's employment status, urban, female household head, number of household members and household assets (electricity, radio, TV, 
refrigerator and bicycle). Robust standard errors in parentheses . *** $\mathrm{p}<0.01, * * \mathrm{p}<0.05, *$ $\mathrm{p}<0.1$ 
Table 8: First Stage Results for Column 4 (and 6) in Table 7

\begin{tabular}{lc}
\hline \hline $\begin{array}{l}\text { Dependent } \\
\text { variable }\end{array}$ & HH owns bed net \\
\hline
\end{tabular}

ITN per capita

$0.230 * * *$

$(0.0662)$

Child age 1

0.00210

$(0.0104)$

Child age 2

$-0.0106$

Child age 3

$(0.00925)$

Child age 3

$-0.0107$

Child age 4

Child age 4

$-0.00518$

$2^{\text {nd }}$ wave dummy

(0.00934)

$0.322 * * *$

(0.0231)

Constant

$-0.146^{*}$

(0.0804)

Observations

11193

R-squared

0.317

Kleibergen-Paap F-Stat

11.65

Kleibergen-Paap weak

0.0014

identification p-value

Notes: Includes control for district fixed effects, sex, mother's age, mother's age squared, mother's education, mother's marital status, mother's employment status, urban, female household head, number of household members and household assets (electricity, radio, tv, fridge and bike).

Robust standard errors in parentheses. ${ }^{* * *} \mathrm{p}<0.01,{ }^{* *} \mathrm{p}<0.05,{ }^{*} \mathrm{p}<0.1$ 
Table 9: Control for baseline level in micro-level regression, DHS

\begin{tabular}{|c|c|c|c|c|c|c|}
\hline \multirow{2}{*}{$\begin{array}{l}\text { Dependent } \\
\text { variable }\end{array}$} & \multicolumn{4}{|c|}{ Child had fever over last two weeks } & \multicolumn{2}{|c|}{ Diarrhea } \\
\hline & (1) & (2) & (3) & (4) & (5) & (6) \\
\hline Household owns & -0.0141 & & & -0.695 & & -0.0429 \\
\hline & $(0.0105)$ & & & $(0.496)$ & & $(0.597)$ \\
\hline $\begin{array}{l}\text { Child slept under } \\
\text { net }\end{array}$ & & -0.00428 & & & & \\
\hline & & $(0.00895)$ & & & & \\
\hline Bed net distribution & & & - & & -0.00656 & \\
\hline & & & $\begin{array}{c}0.104 * * * \\
(0.0364)\end{array}$ & & $(0.0922)$ & \\
\hline Child age 1 & $\begin{array}{c}0.0640^{* *} \\
*\end{array}$ & $\begin{array}{c}0.0644 * * \\
*\end{array}$ & $\begin{array}{c}0.0645^{* *} \\
*\end{array}$ & $\begin{array}{c}0.0665^{* *} \\
*\end{array}$ & $0.181 * * *$ & $0.181^{* * *}$ \\
\hline & $(0.0121)$ & $(0.0121)$ & $(0.0121)$ & $(0.0148)$ & $(0.0328)$ & $(0.0326)$ \\
\hline Child age 2 & $\begin{array}{c}0.0119 \\
(0.0130)\end{array}$ & $\begin{array}{c}0.0129 \\
(0.0130)\end{array}$ & $\begin{array}{c}0.0124 \\
(0.0130)\end{array}$ & $\begin{array}{l}0.00701 \\
(0.0131)\end{array}$ & $\begin{array}{l}-0.0312 \\
(0.0323)\end{array}$ & $\begin{array}{l}-0.0315 \\
(0.0312)\end{array}$ \\
\hline Child age 3 & $\begin{array}{c}- \\
0.0706^{* *} \\
*\end{array}$ & $\begin{array}{c}- \\
0.0704 * * \\
*\end{array}$ & $\begin{array}{c}- \\
0.0700^{* *} \\
*\end{array}$ & $\begin{array}{c}- \\
0.0770^{* *} \\
*\end{array}$ & $-0.194 * * *$ & $-0.195 * * *$ \\
\hline & $(0.0109)$ & $(0.0109)$ & $(0.0110)$ & $(0.0121)$ & $(0.0281)$ & $(0.0265)$ \\
\hline Child age 4 & $\begin{array}{c}- \\
0.122 * * * \\
(0.0115)\end{array}$ & $\begin{array}{c}- \\
0.120^{* * *} \\
(0.0118)\end{array}$ & $\begin{array}{c}- \\
0.122 * * * \\
(0.0116)\end{array}$ & $\begin{array}{c}- \\
0.122 * * * \\
(0.0126)\end{array}$ & $\begin{array}{c}-0.276^{* * *} \\
(0.0263)\end{array}$ & $\begin{array}{c}-0.276^{* * *} \\
(0.0260)\end{array}$ \\
\hline $\begin{array}{l}\text { Baseline fever } \\
\text { preval. }\end{array}$ & $0.867 * * *$ & $0.888 * * *$ & $0.806^{* * *}$ & 0.393 & 0.168 & 0.143 \\
\hline Constant & $(0.0944)$ & $(0.0933)$ & $(0.0973)$ & $(0.400)$ & $(0.227)$ & $(0.495)$ \\
\hline Observations & 11193 & 11027 & 11193 & 11193 & 11187 & 11187 \\
\hline R-squared & 0.136 & 0.135 & 0.136 & -0.229 & 0.065 & 0.065 \\
\hline $\begin{array}{l}\text { Notes: All specific } \\
\text { squared, mother's } \\
\text { household head, nu } \\
\text { fridge and bike). } \\
\text { Robust standard en }\end{array}$ & $\begin{array}{l}\text { ons cont } \\
\text { cation, } 1 \\
\text { ger of ho } \\
\text { s in pare }\end{array}$ & $\begin{array}{l}\text { for distri } \\
\text { ther's ma } \\
\text { hold mei } \\
\text { eses.** }\end{array}$ & $\begin{array}{l}\text { ixed effec } \\
1 \text { status, } m \\
\text { ars and ho } \\
0.01 * *\end{array}$ & $\begin{array}{l}\text { sex, mot } \\
\text { her's emp } \\
\text { ehold ass } \\
0.05 * \mathfrak{p}<\end{array}$ & $\begin{array}{l}\text { s age, motl } \\
\text { ment status } \\
\text { (electricity, }\end{array}$ & $\begin{array}{l}\text { s age } \\
\text { rban, female } \\
\text { dio, tv, }\end{array}$ \\
\hline
\end{tabular}


Table 10: District-level Differences, DHS

\section{Dependent variable: Change in fever prevalence}
(1)
(2)
(3)
(4)
(5)
(6)

Change in ownership $\quad-0.136$

$(0.0935)$

ITN rollout per capita

$$
\begin{array}{ccccc}
-0.188 * * & - & - & -0.0711 * & -0.0761 * \\
& 0.0778^{*} & 0.0778 * & & \\
& * & * & & \\
(0.0739) & (0.0357) & (0.0367) & (0.0399) & (0.0402)
\end{array}
$$

Baseline fever

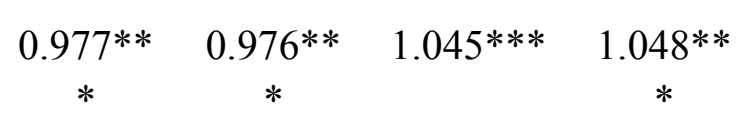

$\begin{array}{llll}(0.0983) & (0.0981) & (0.124) & (0.125) \\ & -0.0452 & -0.0427 & -0.0346\end{array}$

Change in mother $\begin{array}{lll}-0.0452 & -0.0427 & -0.0346\end{array}$

education $\begin{array}{lll}(0.0430) & (0.0416) \quad(0.0407)\end{array}$

Change in mother $-0.0341 \quad-0.0392$ working

Change in average age

$(0.0340) \quad(0.0328)$ $-0.0545$ (0.0558)

Constant

$$
\begin{array}{cccccc}
- & - & 0.191 * * & 0.193 * * & 0.220 * * * & 0.222 * * \\
0.214 * * & 0.222 * * & * & * & & * \\
* & * & & & & \\
(0.0446) & (0.0253) & (0.0428) & (0.0424) & (0.0510) & (0.0515)
\end{array}
$$

Observations

$\begin{array}{cc}70 & 70 \\ 0.044 & 0.107\end{array}$

$\begin{array}{cc}70 & 70 \\ 0.617 & 0.622\end{array}$

70

70

R-squared

0.044

0.107

0.627

0.637

Robust standard errors in parentheses

$* * * \mathrm{p}<0.01, * * \mathrm{p}<0.05, * \mathrm{p}<0.1$ 


\section{Table 11: Bed nets and Child Mortality}

\begin{tabular}{|c|c|c|c|c|c|}
\hline \multirow[t]{2}{*}{ Dependent variable } & \multicolumn{5}{|c|}{ Death of child } \\
\hline & (1) & (2) & (3) & (4) & (5) \\
\hline HH owns bed net & $\begin{array}{l}-0.00968 \\
(0.00690)\end{array}$ & & & & \\
\hline \multirow{2}{*}{$\begin{array}{l}\text { Kids in HH slept with } \\
\text { bed net }\end{array}$} & & - & & & \\
\hline & & $\begin{array}{l}0.0486 * * * \\
(0.00608)\end{array}$ & & & \\
\hline \multirow[t]{2}{*}{ ITN district coverage } & & & $-0.0443 *$ & $-0.0361 *$ & 0.0116 \\
\hline & & & $(0.0255)$ & $(0.0216)$ & $(0.00808)$ \\
\hline \multirow[t]{3}{*}{ Female } & - & - & - & - & - \\
\hline & $0.0199 * * *$ & $0.0199 * * *$ & $0.0199 * * *$ & $0.0185 * * *$ & $0.00540 * *$ \\
\hline & $(0.00538)$ & $(0.00535)$ & $(0.00539)$ & $(0.00489)$ & $(0.00214)$ \\
\hline \multirow[t]{3}{*}{$2^{\text {nd }}$ wave } & - & - & - & - & - \\
\hline & $0.0364 * * *$ & $0.0307 * * *$ & $0.0289 * * *$ & $0.0265 * * *$ & $0.0107 * * *$ \\
\hline & $(0.00629)$ & $(0.00587)$ & $(0.00926)$ & $(0.00805)$ & $(0.00361)$ \\
\hline \multirow[t]{3}{*}{ Sample restrictions } & none & none & none & Last 3 & Last 3 \\
\hline & & & & years & years \\
\hline & & & & & Older 2 \\
\hline \multirow[t]{2}{*}{ Constant } & $0.270 * * *$ & $0.254 * * *$ & $0.271 * * *$ & $0.232 * * *$ & 0.0171 \\
\hline & $(0.0478)$ & $(0.0474)$ & $(0.0479)$ & $(0.0426)$ & $(0.0176)$ \\
\hline Observations & 13201 & 13201 & 13201 & 12835 & 11941 \\
\hline R-squared & 0.032 & 0.036 & 0.032 & 0.034 & 0.022 \\
\hline
\end{tabular}

Notes: All specifications control for age and district fixed effects, mother's age, mother's age squared, mother's education, mother's marital status, mother's employment status, urban, female household head, number of household members and household assets (electricity, radio, tv, fridge and bike).

Robust standard errors in parentheses. ${ }^{* * *} \mathrm{p}<0.01, * * \mathrm{p}<0.05, * \mathrm{p}<0.1$ 
Table 12: Descriptive statistics of district level panel HMIS

\begin{tabular}{lrrrrr}
\hline \hline & Obs & Mean & Std.Dev & Min & Max \\
\cline { 2 - 6 } Malaria inpatients under 5 & 645 & 1922 & 1531 & 0 & 8169 \\
Malaria deaths under 5 & 645 & 55 & 55 & 0 & 325 \\
Other deaths under 5 & 645 & 142 & 181 & 0 & 1770 \\
Nets ('000) & 648 & 9 & 20 & 0 & 182 \\
District population ('000) & 648 & 157 & 153 & 19 & 1341 \\
\cline { 2 - 6 } Malaria inpatients per 1000 children under 5 & 645 & 72.01 & 46.54 & 0 & 343.87 \\
Malaria deaths per 1000 children under 5 & 645 & 1.91 & 1.37 & 0 & 8.81 \\
Other deaths per 1000 children under 5 & 645 & 4.67 & 3.59 & 0 & 21.57 \\
Nets per capita & 648 & 0.06 & 0.12 & 0 & 0.71 \\
\hline
\end{tabular}


Table 13 B: ITN Distribution and Malaria

\begin{tabular}{|c|c|c|c|c|c|c|}
\hline & $\begin{array}{c}\text { Malaria } \\
\text { inpatients } \\
\text { under } 5\end{array}$ & $\begin{array}{c}\text { Malaria } \\
\text { deaths } \\
\text { under } 5\end{array}$ & $\begin{array}{c}\text { Other } \\
\text { deaths } \\
\text { under } 5\end{array}$ & $\begin{array}{c}\text { Malaria } \\
\text { inpatients } \\
\text { under } 5\end{array}$ & $\begin{array}{c}\text { Malaria } \\
\text { deaths } \\
\text { under } 5\end{array}$ & $\begin{array}{c}\text { Other } \\
\text { deaths } \\
\text { under } 5\end{array}$ \\
\hline & (1) & (2) & (3) & (4) & (5) & (6) \\
\hline Nets current year & & & & $\begin{array}{l}-0.680 \\
(1.875)\end{array}$ & $\begin{array}{l}-0.0913 \\
(0.0767)\end{array}$ & $\begin{array}{l}-0.101 \\
(0.169)\end{array}$ \\
\hline $\begin{array}{l}\text { Nets previous } \\
\text { year }\end{array}$ & $-8.888 * * *$ & $-0.255 * * *$ & -0.143 & $-9.422 * * *$ & $-0.342 * * *$ & -0.210 \\
\hline & $(2.307)$ & $(0.0651)$ & $(0.156)$ & $(2.643)$ & $(0.0813)$ & $(0.165)$ \\
\hline $\begin{array}{l}\text { Nets two years } \\
\text { ago }\end{array}$ & & & & -4.856 & $-0.315 * * *$ & $-0.488^{*}$ \\
\hline & & & & $(3.881)$ & $(0.0972)$ & $(0.260)$ \\
\hline Constant & $\begin{array}{c}2263 * * * \\
(53.05)\end{array}$ & $\begin{array}{c}68.53 * * * \\
(2.744)\end{array}$ & $\begin{array}{c}166.9 * * * \\
(4.921)\end{array}$ & $\begin{array}{c}2264 * * * \\
(60.00)\end{array}$ & $\begin{array}{c}68.70 * * * \\
(3.014)\end{array}$ & $\begin{array}{c}167.0 * * * \\
(5.257)\end{array}$ \\
\hline Observations & 573 & 573 & 573 & 501 & 501 & 501 \\
\hline R-squared & 0.872 & 0.741 & 0.904 & 0.881 & 0.774 & 0.904 \\
\hline
\end{tabular}

Robust standard errors in parentheses are clustered at the district level. All specifications include year and district fixed effects. Nets are in thousands.

$* * * \mathrm{p}<0.01, * * \mathrm{p}<0.05, * \mathrm{p}<0.1$ 
Table 13 B: ITN Distribution and Malaria Relative to Population

\begin{tabular}{|c|c|c|c|c|c|c|}
\hline & $\begin{array}{c}\text { Malaria } \\
\text { inpatients } \\
\text { per } 1000 \\
\text { children } \\
\text { under } 5\end{array}$ & $\begin{array}{c}\text { Malaria } \\
\text { deaths } \\
\text { per } 1000 \\
\text { children } \\
\text { under } 5\end{array}$ & $\begin{array}{c}\text { Other } \\
\text { deaths } \\
\text { per } 1000 \\
\text { children } \\
\text { under } 5 \\
\end{array}$ & $\begin{array}{c}\text { Malaria } \\
\text { inpatients } \\
\text { per } 1000 \\
\text { children } \\
\text { under } 5 \\
\end{array}$ & $\begin{array}{c}\text { Malaria } \\
\text { deaths } \\
\text { per } 1000 \\
\text { children } \\
\text { under } 5 \\
\end{array}$ & $\begin{array}{c}\text { Other } \\
\text { deaths } \\
\text { per } 1000 \\
\text { children } \\
\text { under } 5 \\
\end{array}$ \\
\hline & (1) & (2) & (3) & (4) & (5) & (6) \\
\hline Nets per capita & & & & $\begin{array}{c}6.088 \\
(9.872)\end{array}$ & $\begin{array}{l}-0.121 \\
(0.309)\end{array}$ & $\begin{array}{l}-1.543 \\
(1.102)\end{array}$ \\
\hline $\begin{array}{l}\text { L1 nets per } \\
\text { capita }\end{array}$ & $\begin{array}{c}-26.25 * * * \\
(9.279)\end{array}$ & $\begin{array}{c}-0.778 * * * \\
(0.271)\end{array}$ & $\begin{array}{l}-0.709 \\
(0.769)\end{array}$ & $\begin{array}{c}-30.14 * * \\
(12.74)\end{array}$ & $\begin{array}{c}-0.852 * * \\
(0.382)\end{array}$ & $\begin{array}{c}-1.797 * \\
(1.077)\end{array}$ \\
\hline $\begin{array}{l}\text { L2 nets per } \\
\text { capita }\end{array}$ & & & & $\begin{array}{l}-33.50 \\
(36.40)\end{array}$ & $\begin{array}{r}-0.0370 \\
(0.817)\end{array}$ & $\begin{array}{c}-3.839 * * \\
(1.557)\end{array}$ \\
\hline Constant & $\begin{array}{c}59.75 * * * \\
(2.751)\end{array}$ & $\begin{array}{l}1.316^{* * *} \\
(0.0930)\end{array}$ & $\begin{array}{c}3.673 * * * \\
(0.191)\end{array}$ & $\begin{array}{c}89.62 * * * \\
(2.836)\end{array}$ & $\begin{array}{c}2.295 * * * \\
(0.0940)\end{array}$ & $\begin{array}{c}5.334 * * * \\
(0.185)\end{array}$ \\
\hline $\begin{array}{l}\text { Observations } \\
\text { R-squared }\end{array}$ & $\begin{array}{c}573 \\
0.811\end{array}$ & $\begin{array}{c}573 \\
0.634\end{array}$ & $\begin{array}{c}573 \\
0.744\end{array}$ & $\begin{array}{c}501 \\
0.824\end{array}$ & $\begin{array}{c}501 \\
0.637\end{array}$ & $\begin{array}{c}501 \\
0.771\end{array}$ \\
\hline
\end{tabular}

Robust standard errors in parentheses are clustered at the district level. All specifications include year and district fixed effects.

$* * * \mathrm{p}<0.01, * * \mathrm{p}<0.05, * \mathrm{p}<0.1$ 
Table 14: IRS Results, DHS

\begin{tabular}{|c|c|c|c|c|}
\hline \multirow{3}{*}{$\begin{array}{l}\text { Dependent variable } \\
\text { Percentage of district population } \\
\text { sprayed }\end{array}$} & \multicolumn{4}{|c|}{ Child had fever over last two weeks } \\
\hline & (1) & (2) & (3) & (4) \\
\hline & $\begin{array}{l}0.102 * * * \\
(0.0192)\end{array}$ & & & \\
\hline Household sprayed (self-report) & & $\begin{array}{l}0.0482 * * \\
(0.0195)\end{array}$ & $\begin{array}{l}-0.0162 \\
(0.0199)\end{array}$ & \\
\hline $\begin{array}{l}\text { Fraction of households sprayed in } \\
\text { cluster }\end{array}$ & & & & $\begin{array}{l}-0.00778 \\
(0.0394)\end{array}$ \\
\hline Age child & $\begin{array}{c}- \\
0.0367 * * * \\
(0.00277)\end{array}$ & $\begin{array}{c}- \\
0.0367 * * * \\
(0.00277)\end{array}$ & $\begin{array}{c}- \\
0.0206 * * * \\
(0.00330)\end{array}$ & $\begin{array}{c}- \\
0.0207 * * * \\
(0.00331)\end{array}$ \\
\hline $2^{\text {nd }}$ wave dummy & $\begin{array}{l}-0.283 * * * \\
(0.0122)\end{array}$ & $\begin{array}{l}-0.257 * * * \\
(0.0108)\end{array}$ & & \\
\hline Constant & $\begin{array}{l}0.614 * * * \\
(0.0733)\end{array}$ & $\begin{array}{c}0.622 * * * \\
(0.0733)\end{array}$ & $\begin{array}{l}0.361 * * * \\
(0.0919)\end{array}$ & $\begin{array}{l}0.357 * * * \\
(0.0921)\end{array}$ \\
\hline Observations & 11524 & 11523 & 5671 & 5672 \\
\hline R-squared & 0.123 & 0.121 & 0.047 & 0.046 \\
\hline
\end{tabular}

All specifications control for district fixed effects, sex, mother's age, mother's age squared, mother's education, mother's marital status, mother's employment status, urban, female household head, number of household members and household assets (electricity, radio, tv, fridge and bike).

Robust standard errors in parentheses

$* * * \mathrm{p}<0.01, * * \mathrm{p}<0.05, * \mathrm{p}<0.1$ 
Table 15 A: Spraying only vs. spraying and ITN

\begin{tabular}{|c|c|c|c|c|c|c|}
\hline & $\begin{array}{c}\text { Malaria } \\
\text { inpatient } \\
\text { s under } 5\end{array}$ & $\begin{array}{c}\text { Malaria } \\
\text { deaths } \\
\text { under } 5\end{array}$ & $\begin{array}{c}\text { Other } \\
\text { deaths } \\
\text { under } 5\end{array}$ & $\begin{array}{c}\text { Malaria } \\
\text { inpatients } \\
\text { under } 5\end{array}$ & $\begin{array}{c}\text { Malaria } \\
\text { deaths } \\
\text { under } 5\end{array}$ & $\begin{array}{c}\text { Other } \\
\text { deaths } \\
\text { under } 5\end{array}$ \\
\hline & (1) & (2) & (3) & (4) & (5) & (6) \\
\hline \multirow{2}{*}{$\begin{array}{l}\text { Spraying target } \\
\text { dummy }\end{array}$} & -241.5 & $-22.57 *$ & 0.539 & $-308.9^{*}$ & $-24.72 * *$ & -0.278 \\
\hline & (189.1) & (12.15) & $(17.62)$ & (176.4) & (12.12) & (17.28) \\
\hline \multirow{2}{*}{$\begin{array}{l}\text { Lag } 1 \text { Bed nets in } \\
\text { ' } 000\end{array}$} & & & & $-9.351 * * *$ & $-0.298 * * *$ & -0.113 \\
\hline & & & & (2.324) & $(0.0702)$ & $(0.147)$ \\
\hline Constant & $\begin{array}{c}1713 * * * \\
(70.43)\end{array}$ & $\begin{array}{c}42.18^{* * *} \\
(2.690)\end{array}$ & $\begin{array}{c}129.7 * * * \\
(11.44)\end{array}$ & $\begin{array}{c}2262^{* * *} \\
(51.98)\end{array}$ & $\begin{array}{c}68.51 * * * \\
(2.513)\end{array}$ & $\begin{array}{c}166.9^{* * *} \\
(4.905)\end{array}$ \\
\hline Observations & 573 & 573 & 573 & 573 & 573 & 573 \\
\hline R-squared & 0.866 & 0.760 & 0.905 & 0.873 & 0.766 & 0.905 \\
\hline
\end{tabular}


Table 15 B: Spraying only vs. spraying and ITN

\begin{tabular}{|c|c|c|c|c|c|c|}
\hline & $\begin{array}{c}\text { Malaria } \\
\text { inpatients } \\
\text { per } 1000 \\
\text { children } \\
\text { under } 5\end{array}$ & $\begin{array}{c}\text { Malaria } \\
\text { deaths } \\
\text { per } 1000 \\
\text { children } \\
\text { under } 5\end{array}$ & $\begin{array}{c}\text { Other } \\
\text { deaths } \\
\text { per } 1000 \\
\text { children } \\
\text { under } 5\end{array}$ & $\begin{array}{c}\text { Malaria } \\
\text { inpatients } \\
\text { per } 1000 \\
\text { children } \\
\text { under } 5\end{array}$ & $\begin{array}{c}\text { Malaria } \\
\text { deaths } \\
\text { per } 1000 \\
\text { children } \\
\text { under } 5\end{array}$ & $\begin{array}{c}\text { Other } \\
\text { deaths } \\
\text { per } 1000 \\
\text { children } \\
\text { under } 5\end{array}$ \\
\hline & (1) & (2) & (3) & (4) & (5) & (6) \\
\hline Fraction sprayed & $\begin{array}{c}6.199 \\
(9.660)\end{array}$ & $\begin{array}{l}-0.416 \\
(0.370)\end{array}$ & $\begin{array}{c}0.792 \\
(0.559)\end{array}$ & $\begin{array}{c}2.526 \\
(9.760)\end{array}$ & $\begin{array}{l}-0.558 \\
(0.372)\end{array}$ & $\begin{array}{c}0.722 \\
(0.543)\end{array}$ \\
\hline Nets per capita & & & & $\begin{array}{c}-25.38 * * * \\
(9.548)\end{array}$ & $\begin{array}{c}-0.984 * * * \\
(0.257)\end{array}$ & $\begin{array}{l}-0.484 \\
(0.704)\end{array}$ \\
\hline Constant & $\begin{array}{c}55.53 * * * \\
(3.029)\end{array}$ & $\begin{array}{c}1.273 * * * \\
(0.0892)\end{array}$ & $\begin{array}{c}3.421^{* * *} \\
(0.208)\end{array}$ & $\begin{array}{c}59.29 * * * \\
(3.555)\end{array}$ & $\begin{array}{l}1.419^{* * *} \\
(0.0968)\end{array}$ & $\begin{array}{c}3.492 * * * \\
(0.190)\end{array}$ \\
\hline Observations & 573 & 573 & 573 & 573 & 573 & 573 \\
\hline R-squared & 0.809 & 0.656 & 0.787 & 0.811 & 0.661 & 0.787 \\
\hline $\begin{array}{l}\text { Robust standard } \\
\text { year and district } \\
\text { the preceding yea }\end{array}$ & rs in paren & $\begin{array}{l}\text { es are cl } \\
\text { distributi }\end{array}$ & $\begin{array}{l}\text { red at th } \\
\text { and spray }\end{array}$ & $\begin{array}{l}\text { istrict leve } \\
\text { numbers }\end{array}$ & $\begin{array}{l}1 \text { specific } \\
\text { ect progra }\end{array}$ & $\begin{array}{l}\text { ons include } \\
\text { activities in }\end{array}$ \\
\hline
\end{tabular}


Figure 1: Malaria Deaths in HMIS

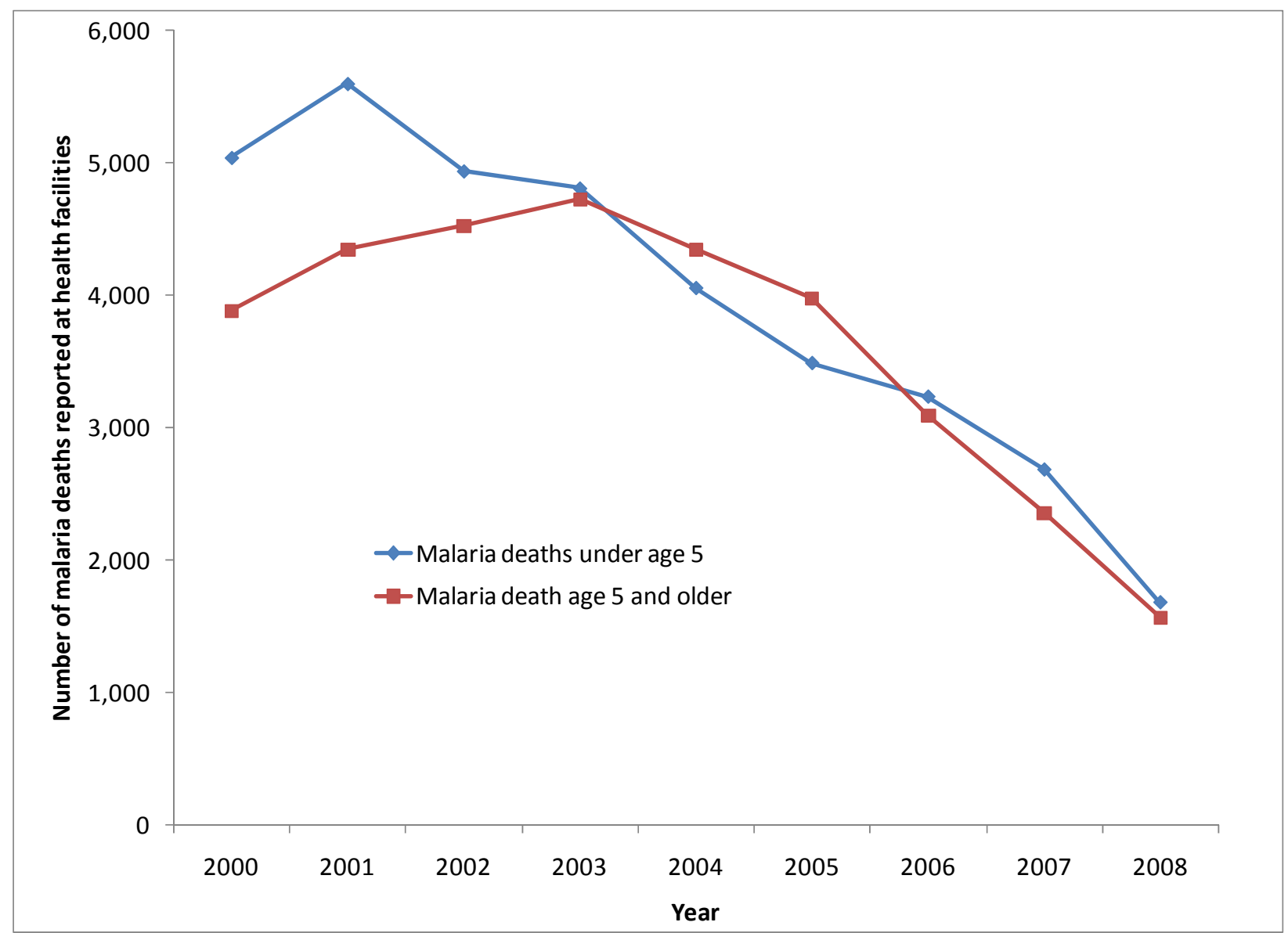


Figure 2: Deaths per 1,000 Children Under 5 in HMIS

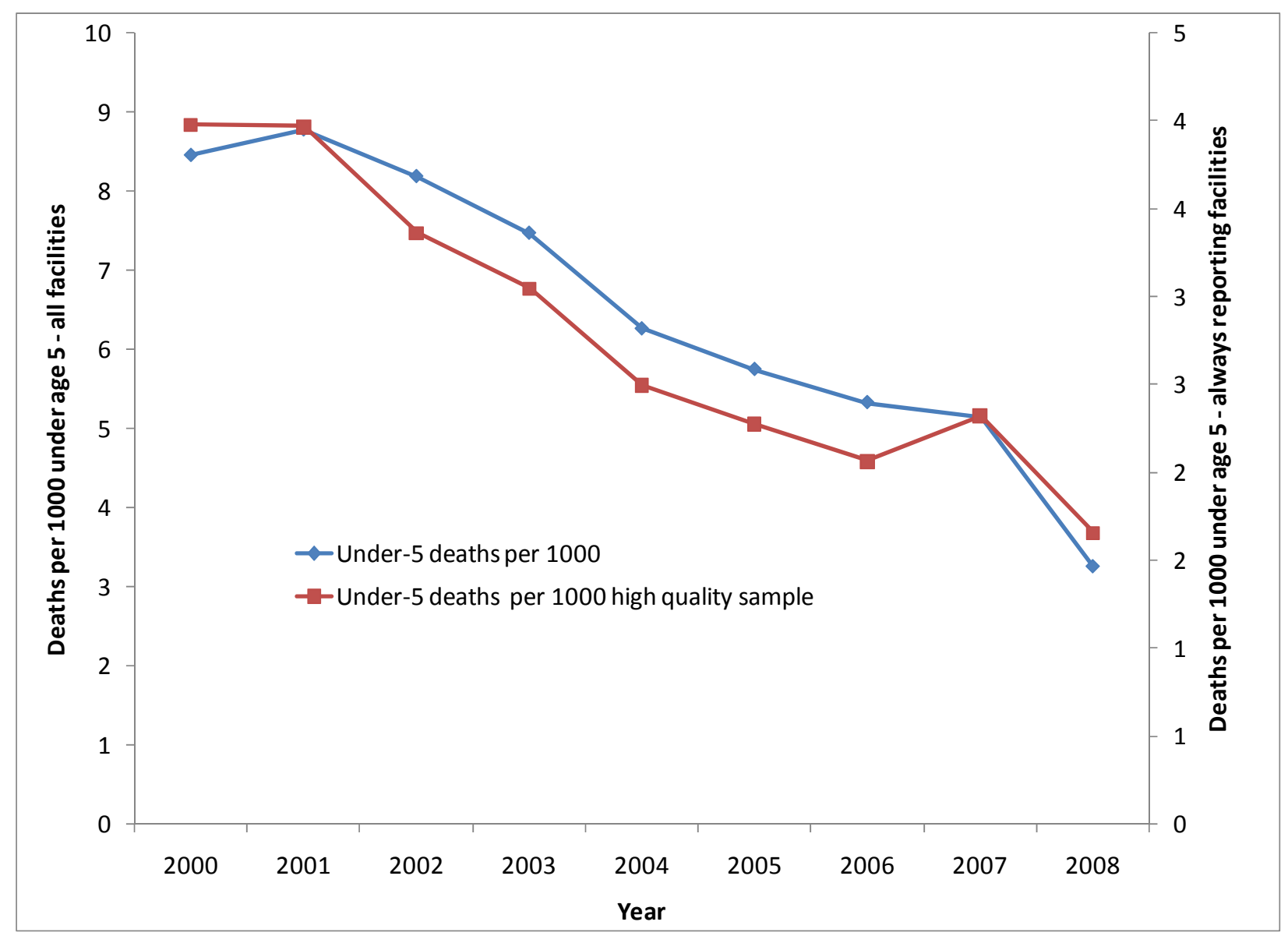


Figure 3: Deaths by Province in DHS vs. HMIS

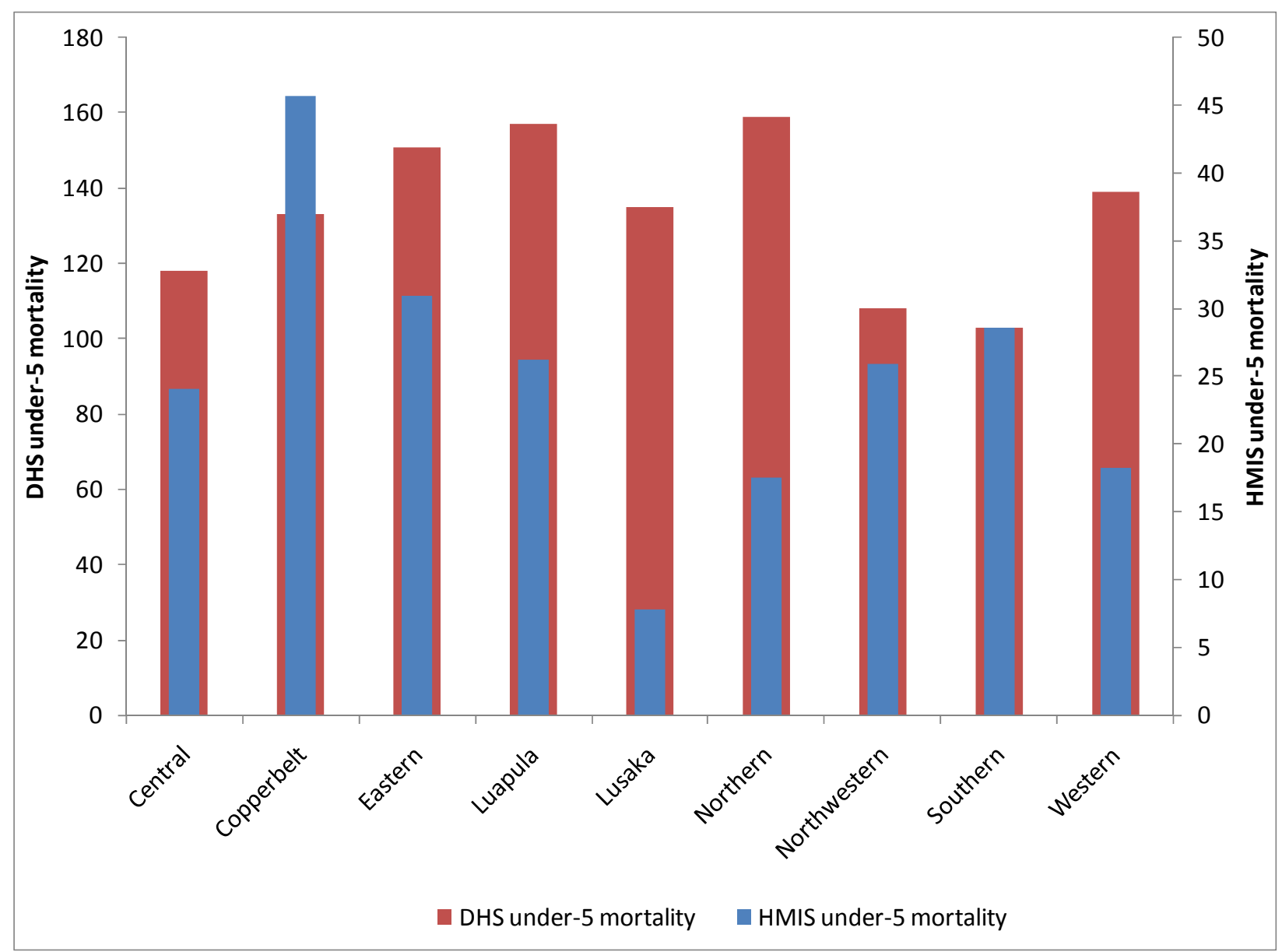


Figure 4: Mortality Changes: HMIS vs. DHS

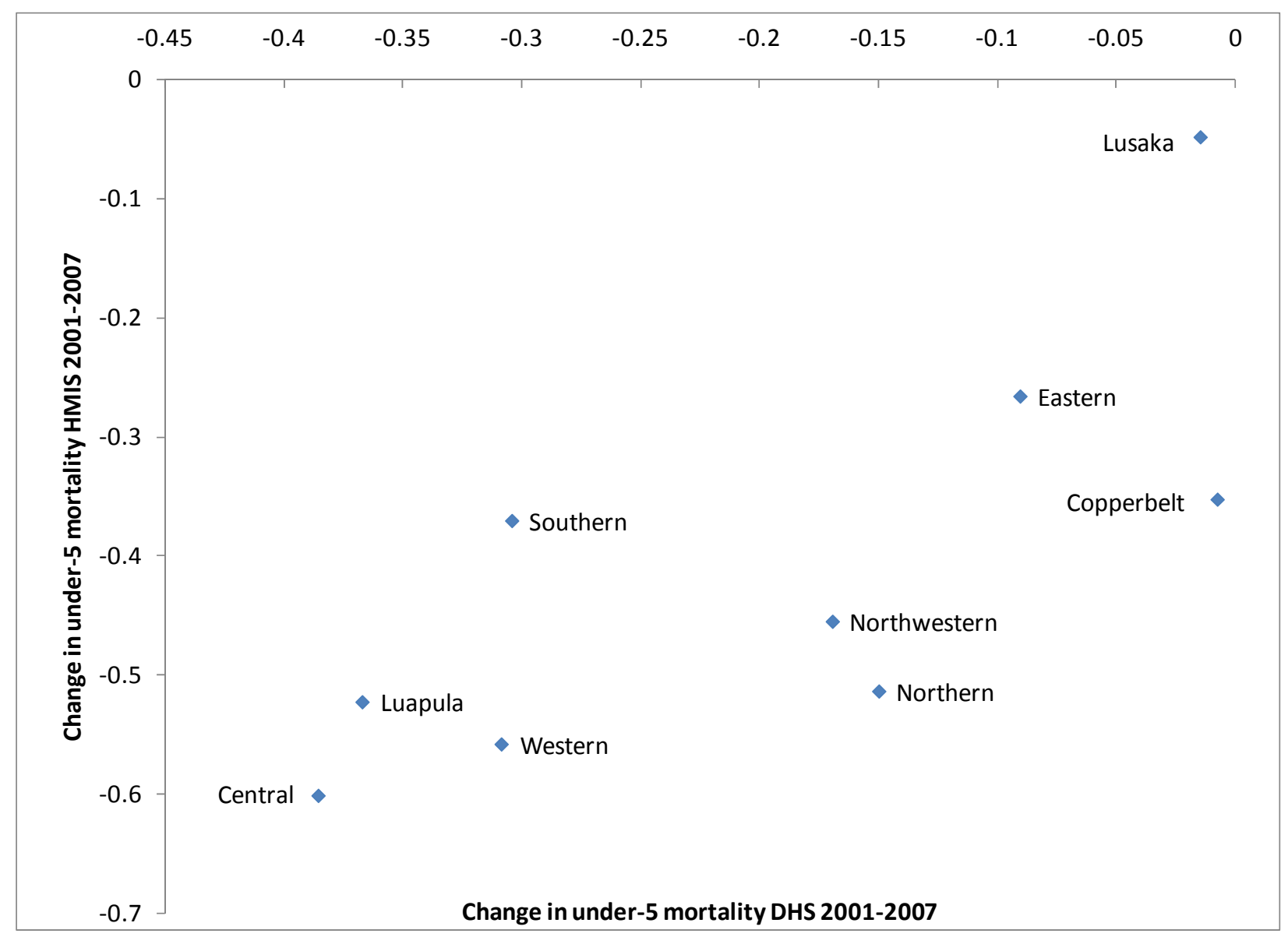

Note: Horzontal axis is change in the under five mortality rate divided by the 2001 level.

Vertical axis is change in HMIS deaths per 1,000 children divided by the 2001 level. 
Figure 5: Malaria Cases and Deaths, Chained Index

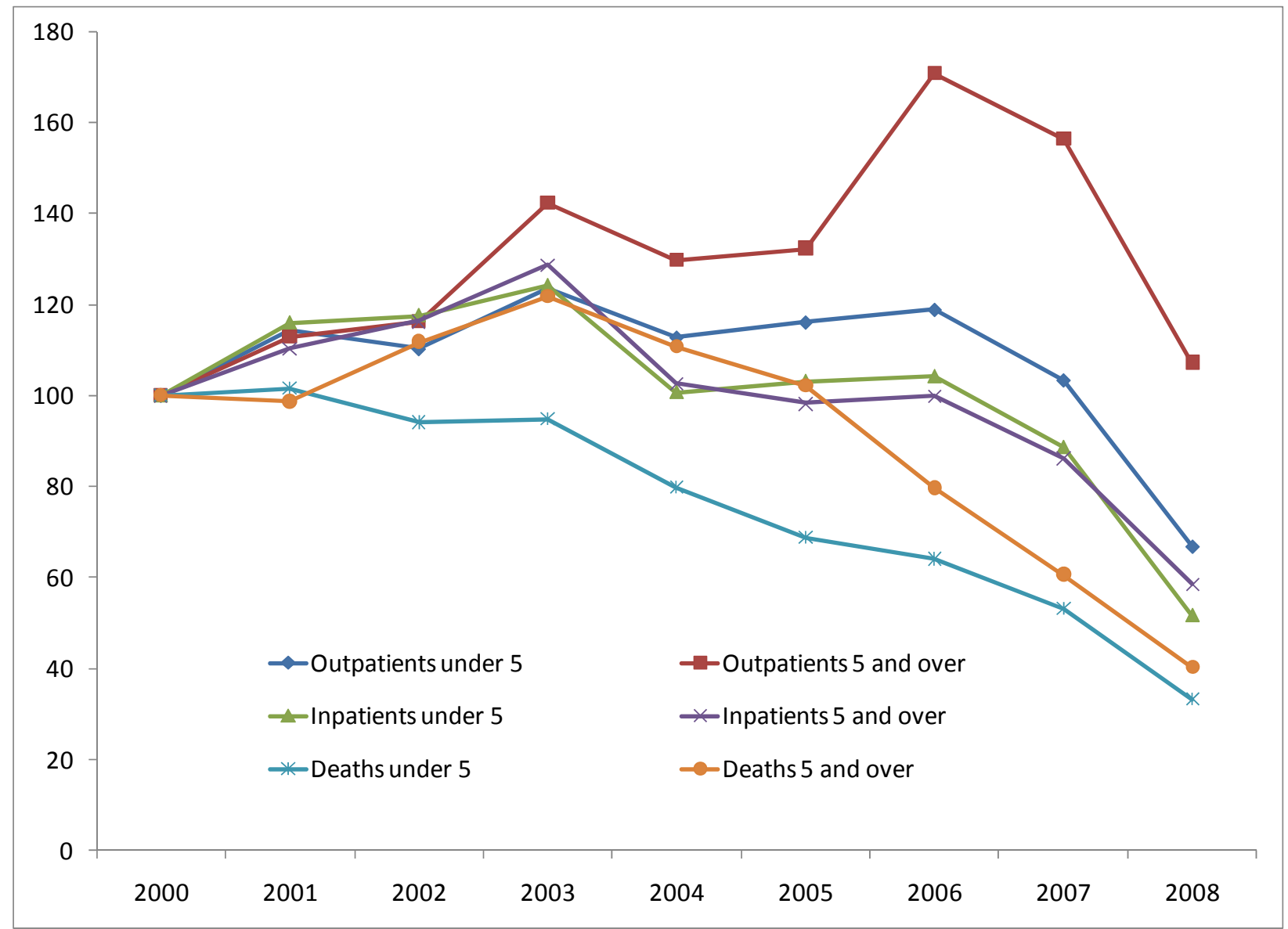

Source: HMIS 
Figure 6: Ratio of Malaria to Non-Malaria Mortality

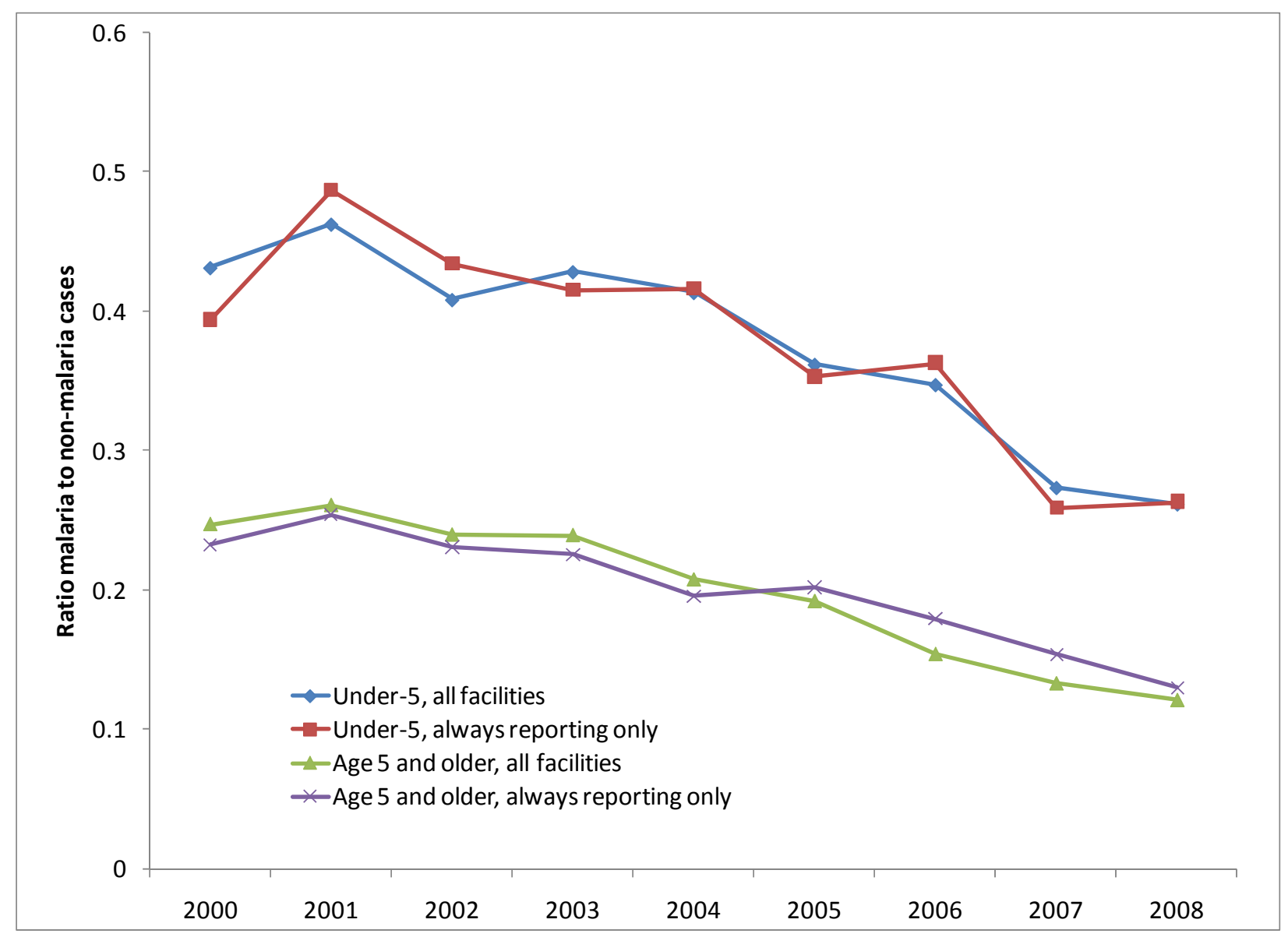

Source: HMIS 
Figure 7: Seasonality of Mortality in the HMIS

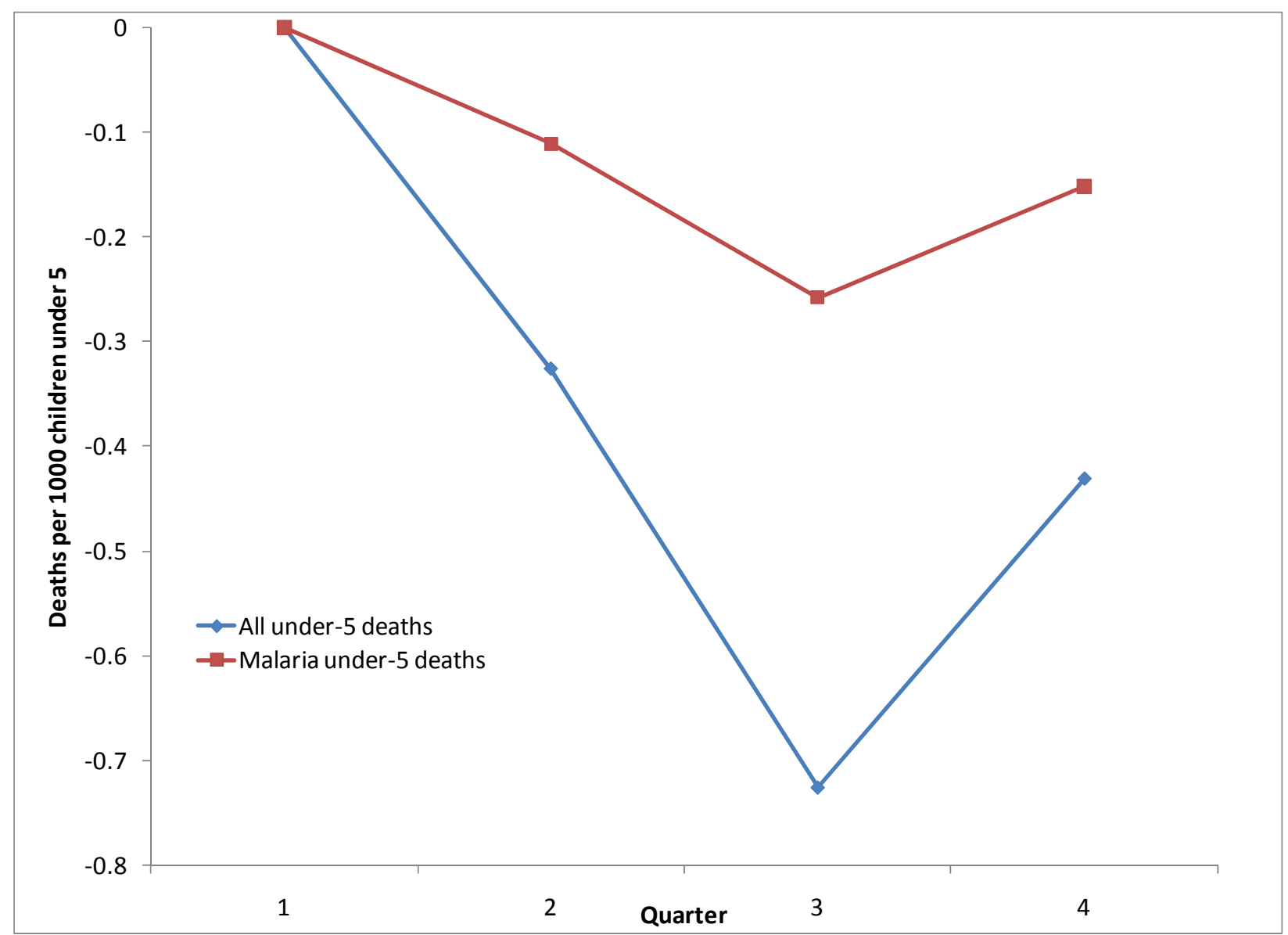

Source: See Table 3. 
Figure 8: Change in Seasonality of Malaria Mortality

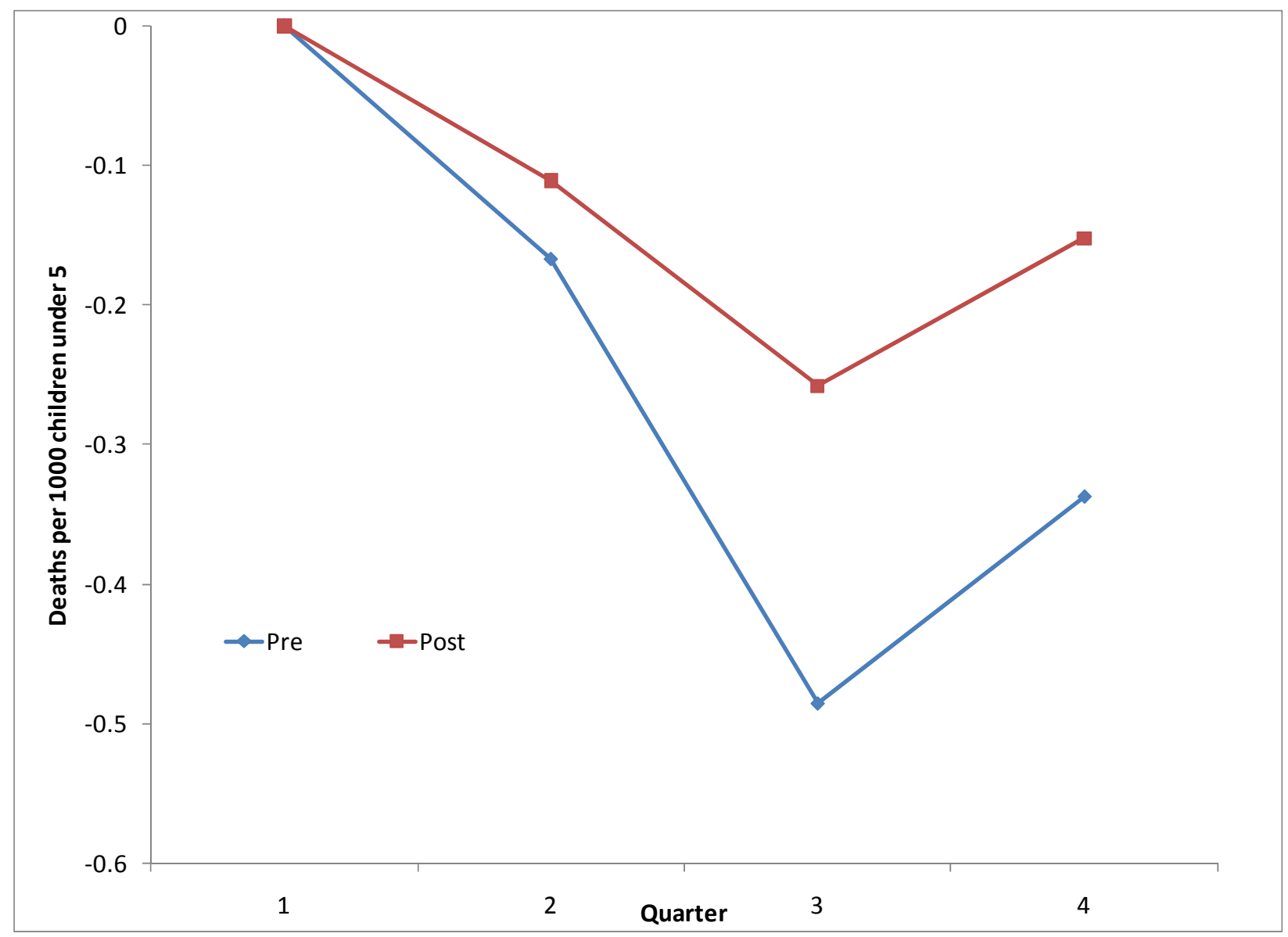

Source: See Table 3. 
Figure 9: Change in the Seasonality of All-Cause Mortality

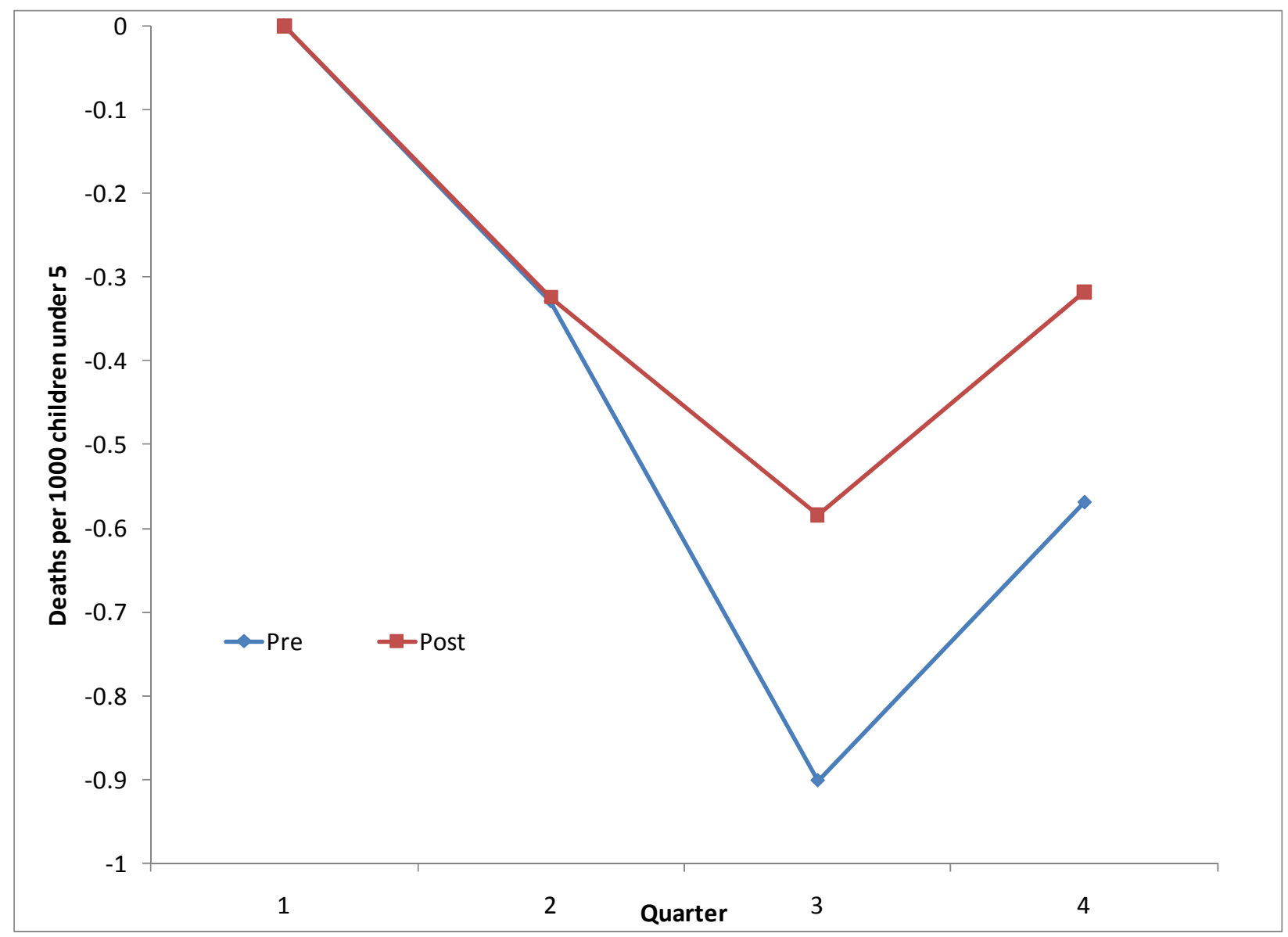

Source: See Table 3. 
Figure 10: IRS Distribution by region
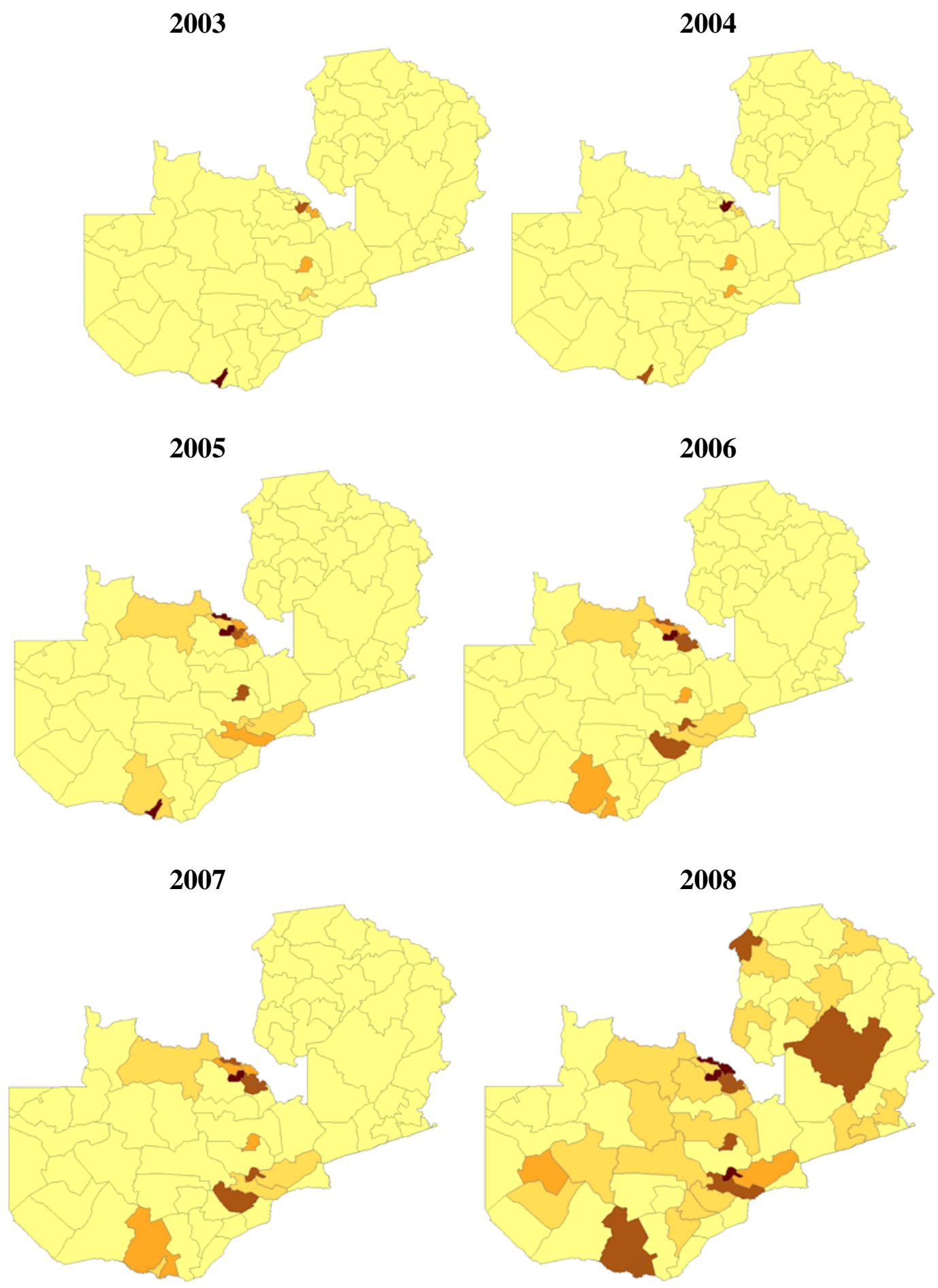
Figure 11: Health Facilities and Spraying in the Chingola District 2008

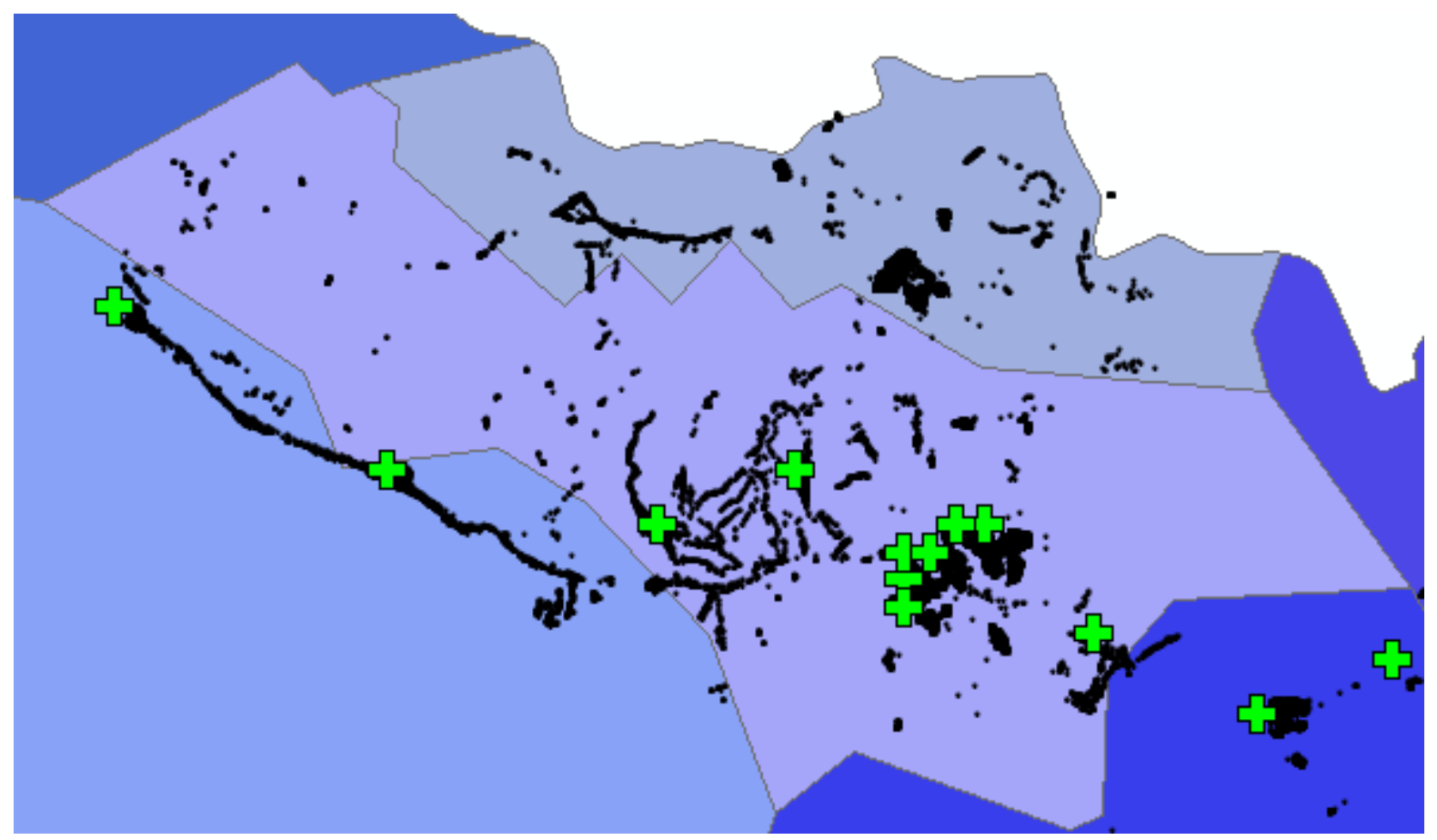

Source: NMCC. Green crosses represent health facilities, black dots sprayed structures. Grey lines are district boundaries. 